\title{
Microwave Plasma Jet in Water: Characterization and Feasibility to Wastewater Treatment
}

\author{
Ahmad Hamdan ${ }^{1,2}$, Jing-Lin Liu ${ }^{1 *}$, and Min Suk Cha ${ }^{1}$ \\ ${ }^{1}$ King Abdullah University of Science and Technology (KAUST), Clean Combustion \\ Research Center (CCRC)/ Physical Science and Engineering Division (PSE), Thuwal 23955, \\ Saudi Arabia \\ ${ }^{2}$ Groupe de physique des plasmas, Département de Physique, Université de Montréal, C.P. \\ 6128, Succ. Centre-ville, Montréal, Québec, H3C 3J7, Canada
}

Email: ahmad.hamdan@umontreal.ca; min.cha@kaust.edu.sa

Keywords: Microwave plasma, plasma in water, water treatment, high-speed imaging, optical emission spectroscopy.

\footnotetext{
* Dalian University of Technology, China
} 


\begin{abstract}
Plasma-liquid interactions have gained escalated interests over the last decade due to their potentials in many applications. The simultaneous generation of physicochemical phenomena of interest promotes itself to the top of the promising technologies for liquid processing. Here, we study the physics of a microwave plasma jet (MWPJ) submerged into water and its feasibility to wastewater treatment. We investigate the plasma and bubble dynamics using highspeed imaging. The effects of the argon flow rate, additive gas, and microwave power on the dynamics are examined highlighting the retreating behaviors of plasma channels due to the losses of electrons and power caused by nearby water surface. The addition of $\mathrm{N}_{2}(<5 \%)$ to $\mathrm{Ar}$ flow results in an oscillatory motion of the foremost edge of the plasma channel. We characterize the submerged MWPJ using a time- and space-averaged optical emission spectroscopy. We found the dominant $\mathrm{OH}(\mathrm{A}-\mathrm{X})$ molecular band and atomic Ar lines with pure Ar flow indicating the effective dissociation of water. Meanwhile, the addition of $\mathrm{N}_{2}$ leads to an intense emission of NH (A-X) molecular band. Finally, we assess the submerged MWPJ as a viable method for water purification based on the degradation of methylene blue (popular model compound). We find a significant improvement in the efficiency by adding 1-3\% of $\mathrm{N}_{2}$ to the Ar, which should be attributed to a combined effects of $\mathrm{NH}$ radicals, having high redox potential, and the backward reactions of $\mathrm{H}_{2} \mathrm{O}_{2}$ to form $\mathrm{OH}$ radicals with $\mathrm{NO}$ and $\mathrm{NO}_{2}$.
\end{abstract}




\section{INTRODUCTION}

To date, numerous plasma sources have been developed and studied for liquid processing [1-3]. They can be classified into two categories: thermal and non-thermal plasma sources. Non-thermal plasmas, including pulsed-nanosecond discharge [4-6], dielectric barrier discharge [7, 8], and plasma jet [9], have been extensively investigated for liquid processing. Such plasmas have shown great potential for controlling the electron induced chemistry [2], because electron energy is selectively augmented while the gas temperature (i.e., the energy of heavy species) is somewhat unchanged. On the other hand, thermal plasmas such as plasma torches [10] and arc jets $[11,12]$ are known to utilize high temperature chemistry as well as plasma generated reactive species (electrons, ions, radicals, photons, etc.).

Gas temperature of non-thermal plasmas remains close to room temperature, even as the electron energy is relatively high (several $\mathrm{eVs}$ ), which gives them an excellent ability to process temperature-sensitive materials such as polymers, biological liquids, and living cells [13-15]. However, despite their unique physical and chemical properties, non-thermal plasmas present some limitations in terms of yields (of process reactions) and/or plasma-device lifetime. When we take the example of in-liquid plasmas generated by nanosecond discharges, these discharges are generated with or without gaseous bubbles, and usually run in spark mode [16-18] (i.e., the plasma channel connects two electrodes) or in streamer mode [4-6] (i.e., the plasma channel is connected to one electrode). In the case of a spark mode, the plasma-electrode interaction is relatively strong, which leads to erosion issue [19-21] and reduces a lifetime of electrodes. In addition, a contamination of plasma treated liquid due to materials from electrode erosion may cause problems, particularly when the size of the particles is very small, and classical purification methods fail to remove them.

Another limitation is related to a process efficiency, which applies to both spark and streamer modes. Admitting the process efficiency is somewhat related with a plasma volume, when chemical and physical aspects of plasma are similar, relatively small in-liquid nonthermal plasmas' volumes $[4,6,16]$ pull down process efficiencies and prevent the non-thermal in-liquid processes from being practically scaled up. Several methods to increase the plasma volume have been previously investigated. One of them is the discharge in biphasic media, either from a gas-liquid or liquid-liquid mixture. An example of this method is the injection of gaseous bubbles into a liquid to facilitate the breakdown and increase the plasma volume [18, $22,23]$. The results obtained with this method are quite remarkable in terms of selectivity [18, 
24-26], which increases the efficiency in removing specific pollutants; however, the plasma volume still remains too small to significantly increase the global efficiency of the processes. In addition, when a size of gaseous bubble is comparable to the inter-electrodes distance, the electrode erosion is also significant $[17,18]$.

Contrary to non-thermal plasmas, thermal plasmas, such as torches and arc jets, provide a good efficiency by combining the chemical reactions induced by plasma species (electrons and ions) with those induced thermally. Our group has recently developed a submerged arc plasma jet to remove organic contaminant (phenol) from water [12], highlighting independent generation of plasma regardless of liquid properties and efficient removal of phenol due to increased plasma volume and its interaction with water. However, the erosion of the electrode could not be avoided, which caused a limited lifetime of the device to several hours as well as secondary contamination.

Although the family of microwave plasmas is classified sometimes as non-thermal plasma or as thermal plasma, depending on the microwave power, the physics of such highfrequency plasma is well known. Recently, microwave discharges in dielectric liquids have been reviewed by Lebedev et al. [2]. Note that the principle of submerging the microwave plasma in water was proposed in 2012 during the VIII International Workshop on Microwave discharges: Fundamentals and Applications by Barkhudarov et al. [27]. Moreover, electrodeless microwave plasma jet (MWPJ), using a surfatron device, in contact with water was proposed by García et al. [28], and it has been tested for methylene blue degradation. Here, we present a submerged MWPJ in water. This setup has the advantages of (i) controlling plasma parameters independently irrespective of liquid properties, (ii) free from electrode erosion, and (iii) providing an efficient water treatment due to increased surface interaction between plasma and treated water as demonstrated in the previous study [12]. Because it is submerged in water, the plasma species can be transported to the entire volume of water due to turbulent mixing. Therefore, in addition to the direct interactions between water and short-lived species (electrons, ions, and photons), other long-lived species (radical, and metastable atoms and molecules) are allowed to interact with water. Such submerged electrodeless MWPJ is thus a promising setup for water treatment. In the present study, we investigate the physical characteristics of the submerged MWPJ highlighting the dynamic behaviors of both bubbles and plasma channels. In addition, in order to examine its feasibility to be applied in water treatment, methylene blue is selected as a simulated organic contaminant, which has many 
previous literatures to compare, and a degradation of methylene blue is presented. To detail the plasma, optical emission spectroscopy identifies plasma generated species and rotational temperatures of plasma particles.

\section{EXPERIMENTAL SETUP}

A schematic of the experimental setup is shown in figure 1. It consists of a surfatron device and a microwave generator, a quartz tube to form a plasma with supplied gas, a water container, and diagnostic systems. The quartz tube is connected to the water container, a squarecylinder made by quartz, having $200 \mathrm{~mL}$ of distilled water in a $300-\mathrm{mL}$ maximum volume (the volume of water is maintained for all tested conditions). The outer- and inner-diameter of the quartz tube are $6 \mathrm{~mm}$ and $4 \mathrm{~mm}$, respectively, and the distance from the bottom of the water container to the quartz tube (plasma inlet) is $5 \mathrm{~cm}$ (figure 1b), thus the location of the plasma inlet is $\sim 5 \mathrm{~cm}$ below the surface of water. The surfatron (SURFATRON60, SAIREM) is positioned as close as possible to the water container, such that the injection length of a plasma jet to the water can be maximized.

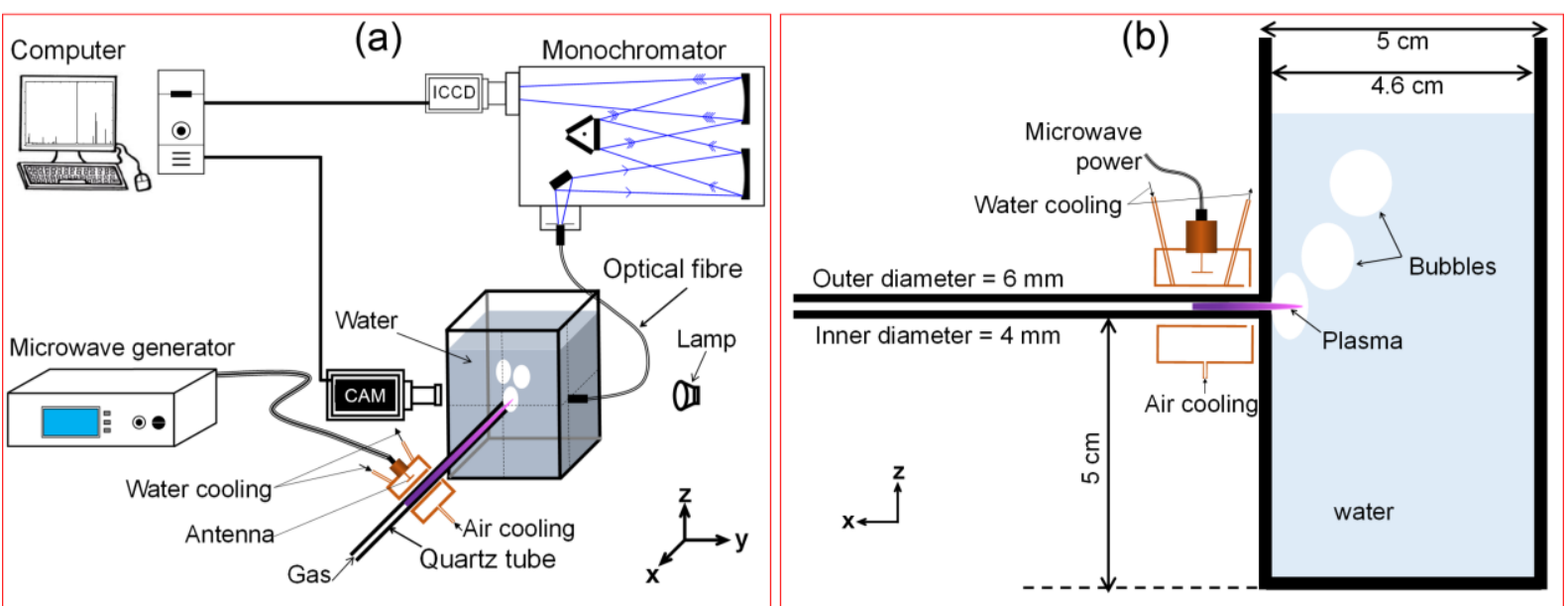

Fig 1 Schematic of the experimental setup used to create submerged MWPJ: a) 3D view and b) $2 D$ view.

A solid-state microwave generator (GMS200W, SAIREM) transmits the microwave at $2.45 \mathrm{GHz}$ via a coaxial cable to the surfatron. A feeding gas (argon, with (or without) nitrogen or oxygen as an additive gas), with a purity of $99.999 \%$, is supplied through the quartz tube using a mass flow controller. To generate the plasma, argon is used as the feeding gas with a flow rate of $1 \mathrm{~L} / \mathrm{min}$ at a standard temperature and pressure condition $\left(20^{\circ} \mathrm{C}\right.$ and $\left.1 \mathrm{~atm}\right)$ and at initial microwave power $(\mu \mathrm{WP})$ of $50 \mathrm{~W}$. As seeding electrons are not enough to absorb the $\mu \mathrm{WP}$ and ignite the plasma, we use a high frequency $(\sim 500 \mathrm{kHz})$ generator (BD-10ASV, ETP) to generate sparks close to the quartz tube providing thus extra electrons that can absorb the 
microwave power and sustain the plasma inside the quartz tube. Then, an operating conditions, such as a gas composition, gas flow rate, and $\mu \mathrm{WP}$ are adjusted after the plasma ignition. Note that to maintain the plasma in a stable manner, the surfatron is cooled by chilled water supplied at $16^{\circ} \mathrm{C}$, and a forced dry air flow between the surfatron and the quartz tube to cool the latter.

To analyze bubble dynamics occurring with MWPJ injected into water, a high-speed imaging is adopted. A high-speed camera (Image Pro HS, LaVision) is placed in the $x-z$ plane shown in figure 1, and a light-emitting diode (LED) lamp (SST-90, Luminus) is located on the other side of the camera to illuminate the area of interest. The exposure time and a framing rate are $0.47 \mathrm{~ms}$ and $2 \mathrm{kHz}$, respectively. An optical emission spectroscopy is also adopted to further investigate detailed characteristics of MWPJ in water, such as plasma species and temperature. A spectrometer (SP2750, Princeton Instruments) equipped with a grating (900 grooves/mm, blazed at visible), an optical fiber (LG-455-020-3, Princeton Instruments), and an ICCD camera (PI-MAX3, Princeton Instrument) is used. The width of the spectrometer's entrance slit is set at $100 \mu \mathrm{m}$, and a resulted spectral resolution of the system is $0.036 \mathrm{~nm}$.

In addition, to evaluate the applicability of the MWPJ for wastewater treatment, the removal of methylene blue $(\mathrm{MB})$ in distilled water is investigated. The tested initial concentration of MB in distilled water is $50 \mathrm{mg} / \mathrm{L}$, and the treated amount of MB contained water is also $200 \mathrm{~mL}$. To estimate a removal efficiency of MB, an UV-Vis spectrophotometer (Genesys 10S, Thermo Scientific) is employed measuring the absorbance of light in a wavelength range from 350 to $1100 \mathrm{~nm}$. As a result, a decolorization efficiency is determined based on the absorbance intensity at $663 \mathrm{~nm}$, which represents MB. Note that, due to a measuring resolution of the spectrophotometer, the liquid samples are diluted 10 times with distilled water. The solution acidity $(\mathrm{pH})$ and electrical conductivity are also measured by a $\mathrm{pH}$ sensor (Inlab Expert Go-ISM, Mettler Toledo) and a conductivity-meter (Inlab 731-ISM, Mettler Toledo), respectively.

\section{RESULTS AND DISCUSSION}

\subsection{Physical characterization of the submerged MWPJ}

High-speed imaging is used to investigate the simultaneous time evolution of a plasma channel and a bubble evaluating the effects of the gas flow rate and the $\mu$ WP. Figure 2 illustrates the instantaneous images of the plasma and the bubble at selected elapsed times. Initial time $(t=0)$ indicates the moment right after a detachment of a previous bubble from the 
inlet of the plasma during a periodic cycle. Each row of the figure represents each tested flow rate of $\operatorname{Ar}$ as $1,2,4$, and $5 \mathrm{~L} / \mathrm{min}$, respectively, while the $\mu \mathrm{WP}$ is fixed at $200 \mathrm{~W}$ (videos are available on demand). It should be noted that the plasma cannot propagate into a bubble with the Ar flow rate smaller than $0.5 \mathrm{~L} / \mathrm{min}$. As a consequence of the increased Ar flow rate, the bubble size increases, therefore, we observe the increased plasma length. In addition to the increased plasma length, an increase in the vertical thickness of the plasma is also observed. Particularly, for higher Ar flow rates (4 and $5 \mathrm{~L} / \mathrm{min}$ ), the plasma channel becomes filamentary at the foremost edge exhibiting the filaments propagate along the gas-water interface perpendicularly to the main horizontal plasma channels (figure 2e).

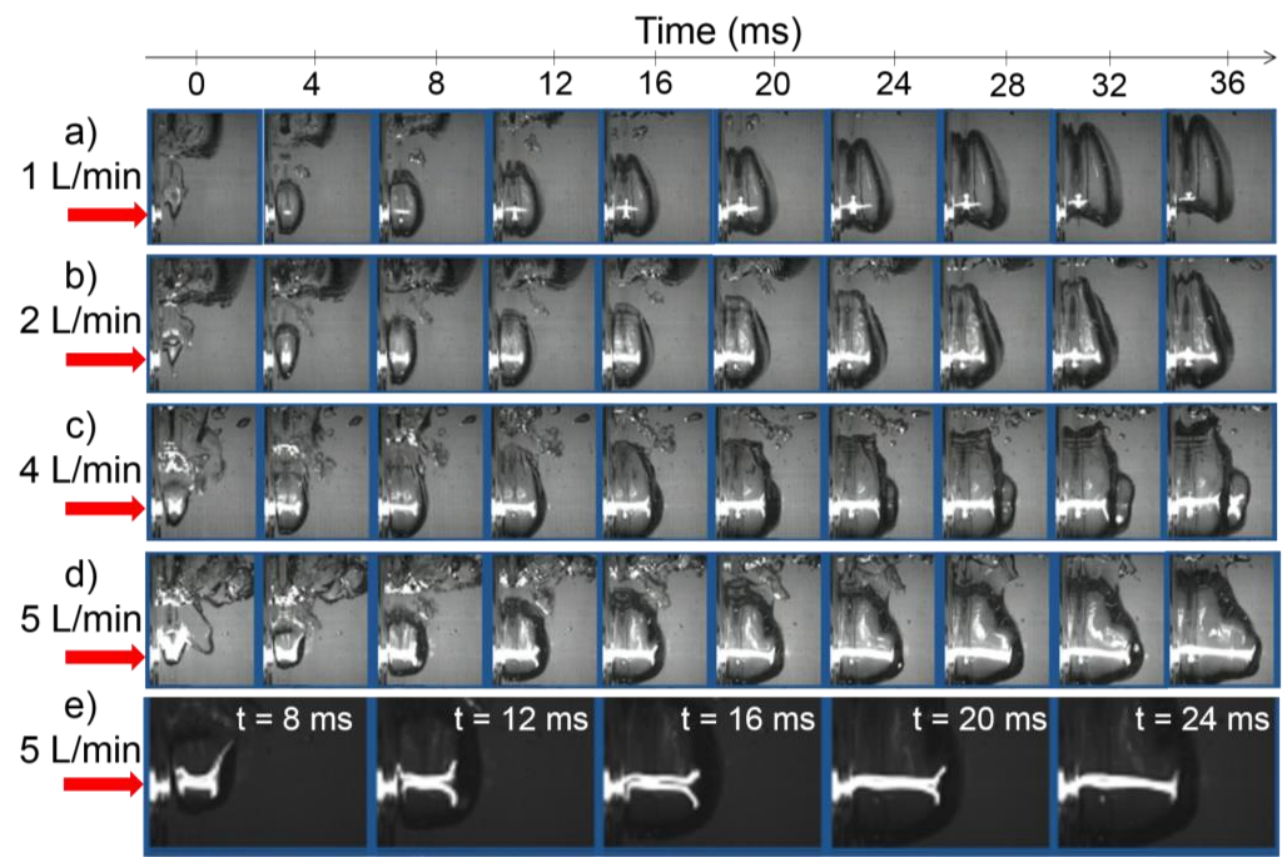

Fig. 2 Plasma-bubble dynamics for various Ar flow rates at $\mu W P=200 \mathrm{~W}$ and water volume $=200 \mathrm{~mL}$ : a) the argon flow rate of $1, b) 2, c) 4$, and d) $5 \mathrm{~L} / \mathrm{min}$; e) is with the same condition as d) but retaken with a higher spatial resolution. The red arrow indicates the plasma inlet and flow direction.

To characterize the dynamics of the plasma and the bubbles, the horizontal lengths of the discharge channel and the bubble are analyzed from the high-speed images, and the results are presented in figure 3. A monotonic increase in the bubble length is observed. The rate of increase slows down along the elapsed time because the rate of increase in bubble's volume, which is related to its cubic length, should be constant with the constant flow rate of Ar. When the bubble length reaches a critical length, the bubble detaches from the side wall and a new successive bubble starts forming repeating the cycle. 

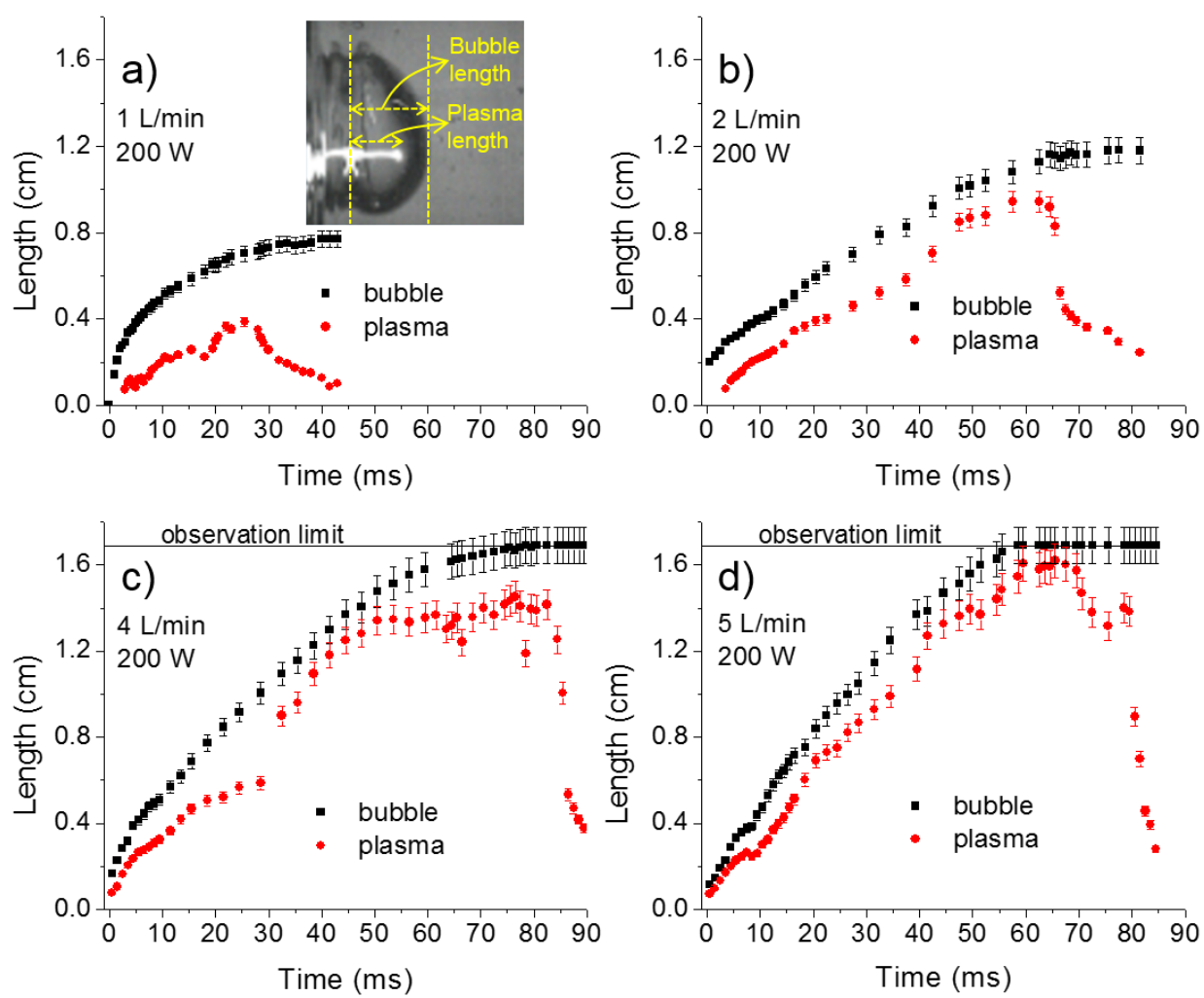

Fig. 3 Time evolution of the plasma length and bubble length for various Ar flow rates at $\mu W P=200 \mathrm{~W}$ and water volume $=200 \mathrm{~mL}:$ a) with the argon flow rate of $1, b) 2, c) 4$, and d) $5 \mathrm{~L} / \mathrm{min}$. These results are obtained from processing the high-speed images. The inset of a) shows the definition of the lengths; the plasma exit (left reference line) is determined based on the plane symmetry due to the reflection from the left side wall.

The plasma length first increases similarly to the bubble length, then, it decreases rapidly. For all tested flow rates, we observe increasing trend of the plasma length as the bubble length increases for a while, but at some instant, the foremost edge of the discharge channel starts to retreat, leading eventually to the total extinction of the plasma in the bubble. This behavior indicates complicated plasma dynamics inside the bubble coupled with water, although the MWPJ into ambient air exhibits a steady plasma channel. We also find that, for the lowest flow rate tested $(1 \mathrm{~L} / \mathrm{min})$, the plasma length is significantly shorter than the bubble length, indicating that the plasma channel cannot reach a bubble-liquid interface. For higher flow rates, the plasma length is comparable to that of the bubble for the initial phase of plasma development. However, a detailed explanation for all these observations cannot be made at this point. Note that the duration of the plasma emission seems to increase with the flow rate, showing a saturated behavior over $4 \mathrm{~L} / \mathrm{min}$ : $\sim 5 \mathrm{~ms}$ and $\sim 80 \mathrm{~ms}$ for 1 and $2 \mathrm{~L} / \mathrm{min}$, respectively, and saturated at $\sim 90 \mathrm{~ms}$ for 4 and $5 \mathrm{~L} / \mathrm{min}$.

To understand the effect of $\mu \mathrm{WP}$ on the dynamics of plasma and bubbles, we vary the $\mu \mathrm{WP}$ from 200 down to $25 \mathrm{~W}$ at a fixed Ar flow rate at $2 \mathrm{~L} / \mathrm{min}$ (figure 4). 

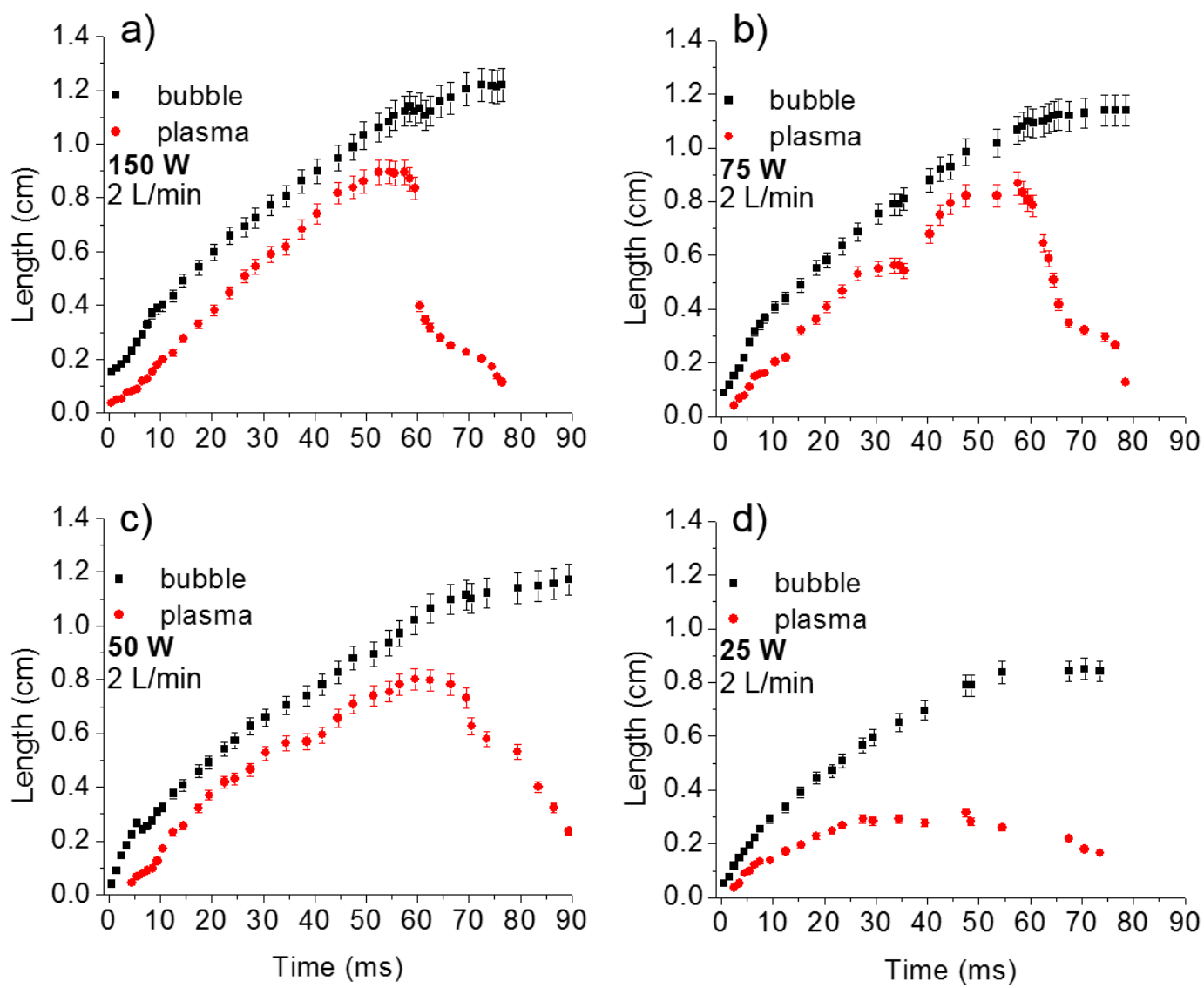

Fig. 4 Time evolution of the plasma length and bubble length for various $\mu W P$ s at the Arflow rate is 2 $\mathrm{L} / \mathrm{min}$ and water volume is $200 \mathrm{~mL}:$ a) $\mu \mathrm{WP}=150 \mathrm{~W}$, b) $75 \mathrm{~W}$, c) $50 \mathrm{~W}$, and d) $25 \mathrm{~W}$.

In terms of the bubble length, we observe that $\mu \mathrm{WP}$ does not affect the final length of the bubble significantly for $\mu \mathrm{WP} \geq 50 \mathrm{~W}$, say it is approximately $1.2 \mathrm{~cm}$. However, for the lowest $\mu \mathrm{WP}$, the bubble length is significantly reduced to $\sim 0.84 \mathrm{~cm}$ at $25 \mathrm{~W}$. Because the $\mathrm{Ar}$ flow rate is fixed at $2 \mathrm{~L} / \mathrm{min}$, the bubble length should be increased being proportional to $\mu \mathrm{WP}$; increased $\mu \mathrm{WP}$ implies increased volume of gas due to both temperature increase and evaporation of water into the bubble. Thus, the present result with the saturated bubble length indicates a non-spherical (anisotropic) evolution of the bubble caused by competition between horizontal jet momentum and vertical buoyant force.

The behaviors of the plasma length in the propagating regime of the plasma channel for $\mu \mathrm{WP} \geq 50 \mathrm{~W}$ are similar to each other (figures $\mathbf{4 a - c}$ and $\mathbf{3 b}$ ), exhibiting a quasilinear increase until the plasma channel reaches its maximum length. For instance, the maximum lengths of the plasma channels are approximately $0.94,0.89,0.86$, and $0.8 \mathrm{~cm}$ at $\mu \mathrm{WP}=200,150,75$, and $50 \mathrm{~W}$, respectively, and each characteristic time to reach the maximum is around $62,55,55$, and $60 \mathrm{~ms}$. The gap distance between the edge of the plasma and the bubble-water interface keeps consistently at around $1 \mathrm{~mm}$ throughout the propagation irrespective of $\mu \mathrm{WP}$. However, 
at $\mu \mathrm{WP}=25 \mathrm{~W}$, the maximum plasma length is very short $(\sim 0.3 \mathrm{~cm})$ demonstrating relatively large separation of the plasma edge from the bubble-water interface (by $\sim 6 \mathrm{~mm}$ ), although a quasilinear increase is also found in the propagating regime. However, the variation of the plasma length in the retreating regime is gradually changed as $\mu \mathrm{WP}$ decreases: from a rapidly shrinking feature for a high $\mu \mathrm{WP}$ to a slowly retreating plasma edge at a low $\mu \mathrm{WP}$. Note that the time durations of active plasma channels fall similarly in a range of 80-90 ms, regardless of $\mu \mathrm{WP}$.

A typical plasma length of the MWPJ into ambient air is $\sim 5 \mathrm{~cm}$ at the Ar flow rate of 2 $\mathrm{L} / \mathrm{min}$ and $\mu \mathrm{WP}=200 \mathrm{~W}$, thus a continuous elongation of the plasma channel, up to the maximum bubble length was naturally expected. However, because the gas is injected horizontally, an anisotropic expansion and upward movement of a bubble, even before detachment, should cause a retreating edge of the plasma channel. An horizontal bubble expansion should be mostly due to the jet momentum, thus the bubble length should exhibit a saturated behavior where a horizontal jet momentum is zero at the bubble-liquid interface, for a given gas flow rate. Meanwhile, a vertical expansion should be due to a mass conservation, and the shape and overall upward movement of the bubble should be due to the buoyancy force acting on the bubble. Because of the upward movement of the bubble, the plasma channel is exposed to a liquid surface at the bottom of the bubble. The water surface could easily absorb both the electrons from the plasma channel and the microwave power, resulting in the gradual quenching of the plasma.

In order to investigate physiochemical characteristics of the submerged MWPJ into water, we perform an optical emission spectroscopy. Light emission near the inlet of the MWPJ into the water container is collected using an optical fiber and analyzed using the spectrometer. Note that all the light emitted from the region inlet-water container is collected providing thus a time- and space-averaged measurements. The spectra presented in figure $\mathbf{5}$ are acquired by varying the $\mu \mathrm{WP}$, at a fixed Ar flow rate of $2 \mathrm{~L} / \mathrm{min}$ and a fixed volume of water at $200 \mathrm{~mL}$. The exposure time for each spectrum recorded is $1 \mathrm{~ms}$, and 50 spectra are averaged for each tested $\mu \mathrm{WPs}$. As shown in figure 5, the $\mathrm{OH}(\mathrm{A}-\mathrm{X})$ band and the $\mathrm{Ar} I$ lines are the most dominant emissions; $\mathrm{H}(\alpha, \beta$, and $\gamma), \mathrm{O} \mathrm{I}$, and $\mathrm{NH}(\mathrm{A}-\mathrm{X})$ bands are also identified. Note that the $\mathrm{NH}$ emission, even with pure Ar, might be due to an impurity in the Ar or air dissolved into water. As $\mu \mathrm{WP}$ increases, overall emission intensity also increases. 


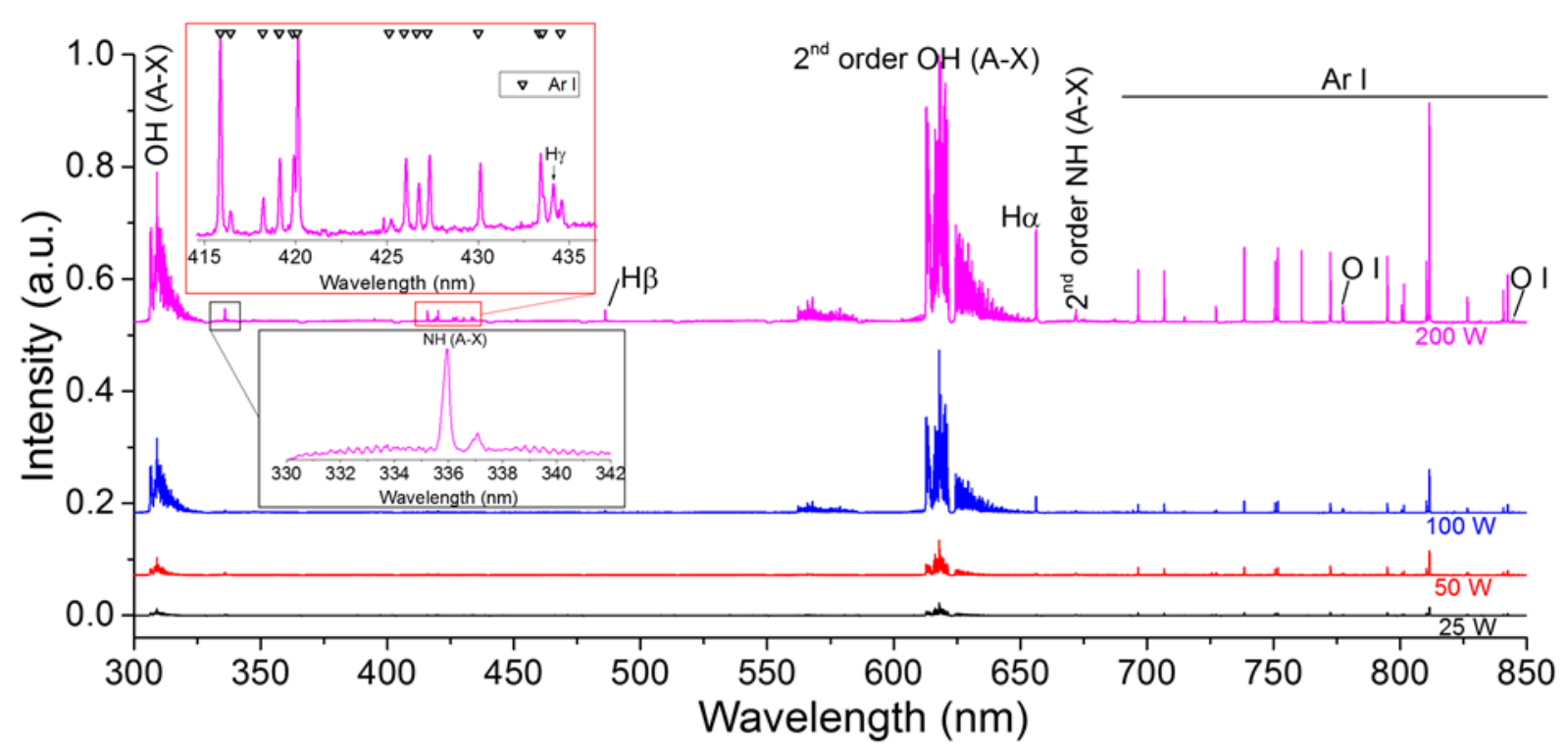

Fig. 5 Optical emission spectra acquired at the inlet of the MWPJ to the liquid cell for four $\mu W P s$ (25, 50,100 , and $200 \mathrm{~W}$ ). Exposure time is $1 \mathrm{~ms}$, each spectrum is averaged 50 measurements, Ar flow rate is $2 \mathrm{~L} / \mathrm{min}$, and the water volume is $200 \mathrm{~mL}$.

To estimate the rotational temperature of plasma particles $\left(T_{r o t}\right)$, we use the measured $\mathrm{OH}$ spectra by adopting the fitting method developed by Rodrigo et al. [29], and the results are shown in figures $\mathbf{6 a}$ and $\mathbf{b}$. As a result, we find that the temperature increases from $~ 1300$ to $\sim 3200 \mathrm{~K}$ as the $\mu \mathrm{WP}$ increases from 25 to $200 \mathrm{~W}$ (figure $\mathbf{6 c}$ ). The reason that the rotational temperature is not proportional to the $\mu \mathrm{WPs}$ is partly due to a higher heat loss for a condition with a higher temperature difference between the plasma channel and the surrounding media. It should be noted that the measured $T_{r o t}$ is in reasonable agreement with those values reported for microwave discharges at atmospheric pressure [30, 31].
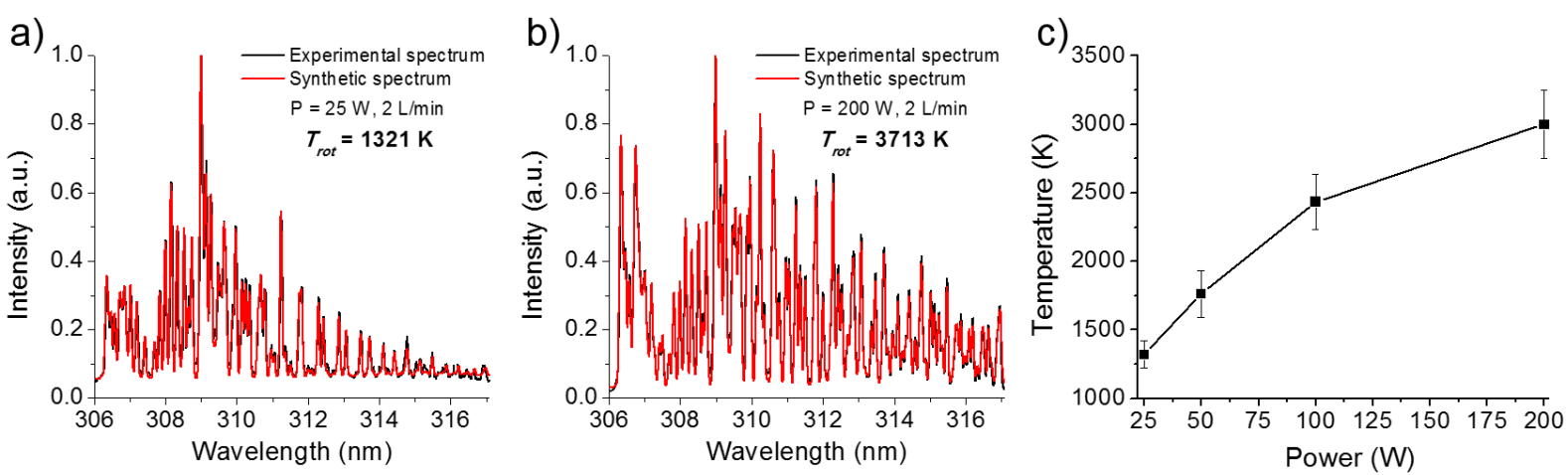

Fig. 6 Experimental and synthetic spectra of $\mathrm{OH}(\mathrm{A}-\mathrm{X})$ at a) 25 and b) $200 \mathrm{~W}$, respectively. c) Rotational temperature variation as a function of $\mu W P$; total Ar flow rate is $2 \mathrm{~L} / \mathrm{min}$ and water volume is $200 \mathrm{~mL}$.

Because the emission from $\mathrm{OH}$ radicals is dominant in the spectrum, we believe it is important to resolve its spatial origin and temporal dynamics. Using a narrow-band-pass optical filter centered at $309 \mathrm{~nm}(\mathrm{FWHM}=10 \mathrm{~nm})$, we perform filtered imaging to spatially resolve 
the $\mathrm{OH}$ emission. Results presented in figure 7 are for various Ar flow rates, at $\mu \mathrm{WP}=200 \mathrm{~W}$. The emission dynamics of $\mathrm{OH}$, for an increasing Ar flow rate, are similar to those from the global emission previously discussed, showing distributed emission along the plasma channel. At $5 \mathrm{~L} / \mathrm{min}$, although the channel seems to be hollow, there is an actual filamentation, and the hollow structure is due to the inter-channels space.

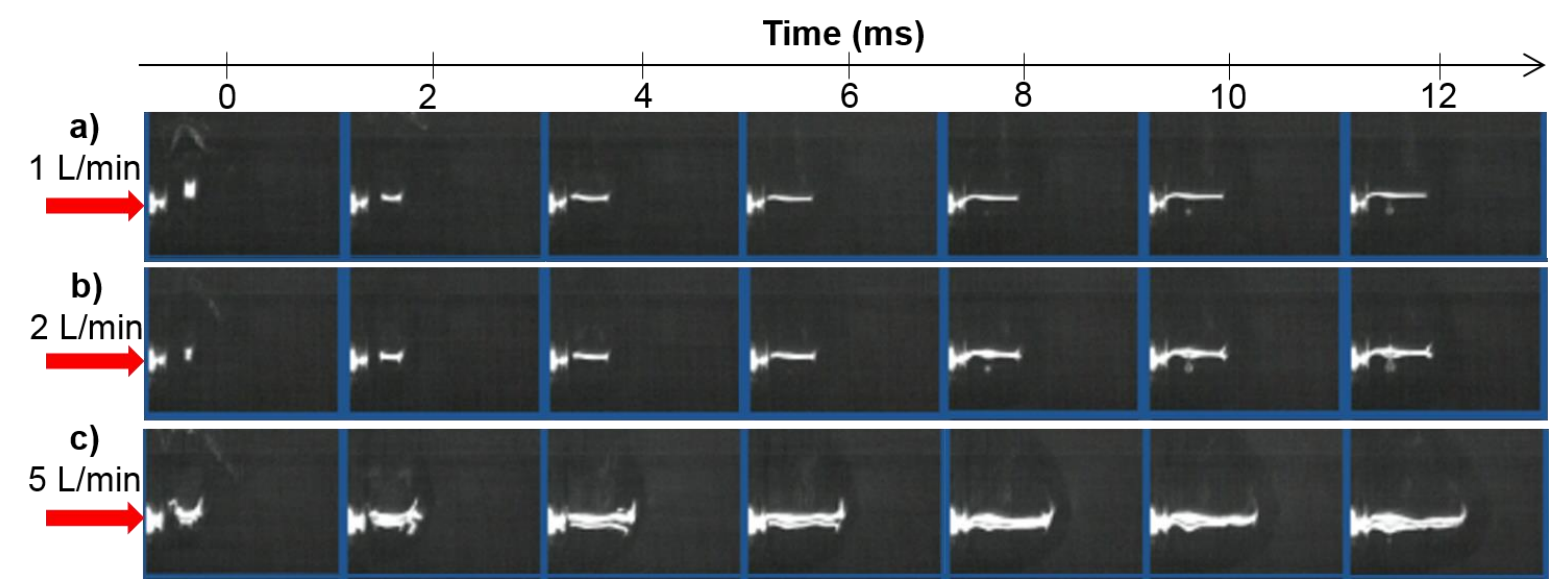

Fig. 7 Temporal dynamics of $\mathrm{OH}(309 \pm 5 \mathrm{~nm})$ emission for various Ar flow rates; a) the argon flow rate of $1, b$ ) 2, and c) $5 \mathrm{~L} / \mathrm{min}$. $\mu \mathrm{WP}$ is $200 \mathrm{~W}$ and water volume is $200 \mathrm{~mL}$. The red arrow indicates the plasma inlet and flow direction.

\subsection{Effects of additive nitrogen on the submerged MWPJ}

To further apply the submerged MWPJ for water treatment, we investigate the effects of gas additives to the Ar stream on the discharge dynamics. Here, we present the results obtained for $\mathrm{N}_{2}$ only, omitting the results with oxygen and air because the bubble and plasma dynamics obtained for oxygen and air are found to be similar to those obtained with nitrogen. Figure 8 shows a selection of instantaneous images for two different $\mathrm{N}_{2}$ percentages, $0.5 \%$ and $2 \%$, respectively, for $\mu \mathrm{WP}$ at $200 \mathrm{~W}$, total gas flow rate of $2 \mathrm{~L} / \mathrm{min}$, and water volume of 200 $\mathrm{mL}$. We find that the size of a bubble is not significantly affected by the percentage of $\mathrm{N}_{2}$, since the size is mostly governed by the flow rate and thermodynamics. For $0.5 \%$ of $\mathrm{N}_{2}$ (and for up to $1 \%$ ), the change in the plasma length is insignificant compared to that observed for pure Ar. However, at $2 \%$ of $\mathrm{N}_{2}$, the plasma length is significantly reduced, and with further addition of $\mathrm{N}_{2}$ (e.g., at $5 \%$ ), no plasma can be found in the bubble. 


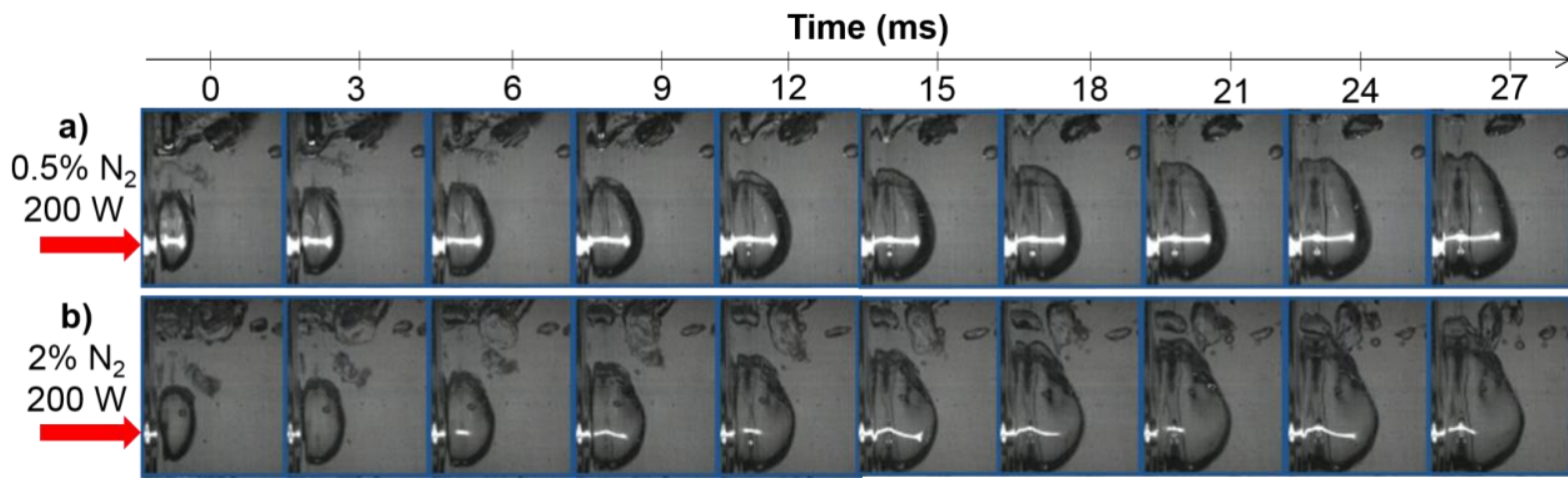

Fig. 8 Plasma-bubble dynamics for two $\mathrm{N}_{2}$ percentages in Ar: a) 0.5 and b) $2 \%$. $\mu \mathrm{WP}$ is $200 \mathrm{~W}$, total gas flow rate is $2 \mathrm{~L} / \mathrm{min}$, and water volume is $200 \mathrm{~mL}$. The red arrow indicates the plasma inlet and flow direction.

We analyze the lengths of the bubble and the discharge channel adopting the same method conducting in figure 3 to compare the plasma and bubble dynamics with the addition of $\mathrm{N}_{2}$. Results are presented in figure 9 for various percentages of $\mathrm{N}_{2}$ in Ar flow comparing the corresponding pure Ar cases as a reference. As aforementioned, the change in the bubble length is negligible irrespective of $\mathrm{N}_{2}$ portion. In terms of the plasma dynamics, we observe that, at $0.5 \%$ of $\mathrm{N}_{2}$, the increasing trend of the plasma length is similar to that of pure Ar, while it reaches its maximum length at $\sim 50 \mathrm{~ms}$, i.e., earlier than that with pure $\operatorname{Ar}(\sim 65 \mathrm{~ms})$. We also find that the duration of the plasma channel is similar to that obtained with pure Ar (figure 9a). At $1 \%$ of $\mathrm{N}_{2}$, the duration is also similar, but the retreating of the foremost discharge edge appears at $\sim 45 \mathrm{~ms}$ (earlier than for $0.5 \% \mathrm{~N}_{2}$ ), exhibiting a shorter maximum plasma length, $\sim 6$ $\mathrm{mm}$, than that obtained with pure Ar, $\sim 9 \mathrm{~mm}$ (figure 9b). For $\mathrm{N}_{2}$ percentage higher than $1.5 \%$, the typical monotonic increasing and decreasing behavior of the plasma length is not observed anymore. Particularly at $1.5 \% \mathrm{~N}_{2}$, it shows 'hump and pit' in its temporal trail demonstrating comparable maximum length of the plasma to that obtained with pure Ar (figure 9c). At $2 \%$ of $\mathrm{N}_{2}$, the oscillatory behavior of the plasma length is more pronounced showing multiple peaks in length (figure 9d). At $3 \%$ of $\mathrm{N}_{2}$, although some oscillations can be observed in the early stage, the oscillatory behavior seems to diminish after $40 \mathrm{~ms}$ accompanied by a significant reduction of the plasma channel in length. Finally, at $5 \%$ of $\mathrm{N}_{2}$, no discharge channel is observed in the bubble, but a tiny plasma close to surfatron can be observed. 

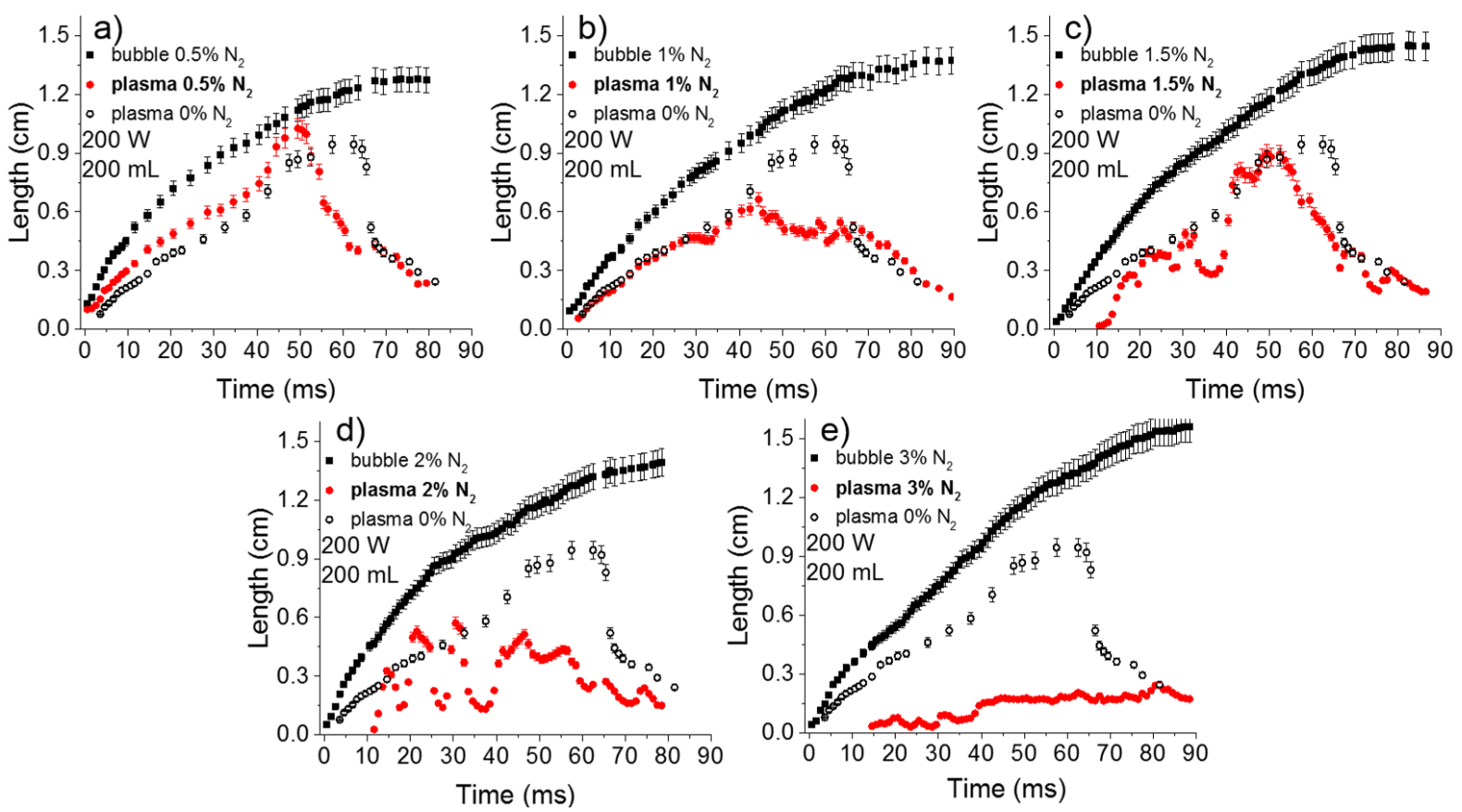

Fig. 9 Time evolution of the plasma and bubble lengths for various $N_{2}$ percentages in Arflow: $\left.a\right)$ 0.5, $b$ ) 1, c) 1.5, d) 2, and e) 3\%. The plasma lengths at 0\% $\mathrm{N}_{2}$ (pure Ar) is superimposed each graph for comparison. Total gas flow rate is $2 \mathrm{~L} / \mathrm{min}, \mu \mathrm{WP}$ is $200 \mathrm{~W}$, and water volume is $200 \mathrm{~mL}$.

The role of $\mathrm{N}_{2}$ in plasma has been extensively studied for gas discharges at atmospheric pressure. It was reported, for example, that a significantly reduced plasma length was the result of the addition of $\mathrm{N}_{2}$. This could possibly be related to a high energy dissipation to the vibrational excitation of $\mathrm{N}_{2}$ and/or a destruction of metastable Ar atoms by quenching reaction with $\mathrm{N}_{2}$ and $\mathrm{N}_{2}{ }^{+}$molecules [32]. It should be noted that no afterglow zone is observed in the submerged MWPJ we investigated, although it is usually observed in discharges at atmospheric pressure once $\mathrm{N}_{2}$ is added to $\mathrm{Ar}[30]$.

Figure 10 shows the variations of the optical emission spectra for a wavelength range of $300-400 \mathrm{~nm}$, at various $\mathrm{N}_{2}$ percentages. As a result of the addition of $\mathrm{N}_{2}$, we can identify emissions from $\mathrm{NH}, \mathrm{N}_{2}$, and $\mathrm{N}_{2}{ }^{+}$. Note that, once again, the $\mathrm{NH}$ emission for the case of pure Ar should be attributed to an impurity in the Ar or air dissolved into water. The emission intensity of $\mathrm{NH}(\mathrm{A}-\mathrm{X})$ at $336 \mathrm{~nm}$ is drastically increased with the addition of $\mathrm{N}_{2}$ showing comparable intensity to that of $\mathrm{OH}(\mathrm{A}-\mathrm{X})$ at $309 \mathrm{~nm}$. Higher intensities of both $\mathrm{NH}$ and $\mathrm{OH}$ emissions are obtained with smaller additions of $\mathrm{N}_{2}$, and increasing amount of $\mathrm{N}_{2}$ leads to a degradation of the plasma generated radicals as shown in figure 9. 


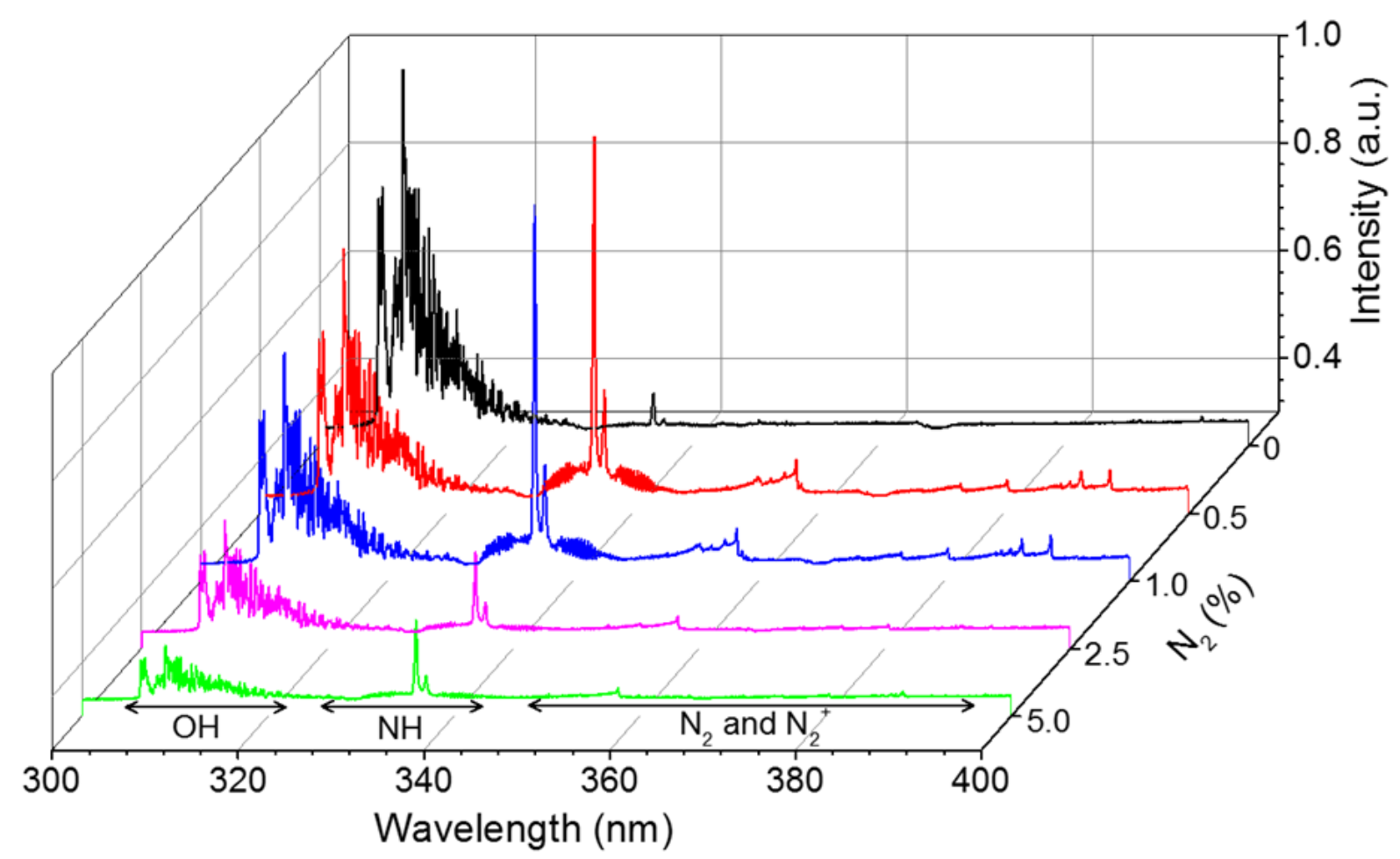

Fig. 10 Plasma optical emission spectra, in a range of 300-400 $\mathrm{nm}$ acquired at the inlet of the MWPJ into the liquid container for various $\mathrm{N}_{2}$ percentages. The integration time is $1 \mathrm{~ms}$, and spectra are averaged over 50 measurements; $\mu \mathrm{WP}$ is $200 \mathrm{~W}$, total gas flow rate is $2 \mathrm{~L} / \mathrm{min}$, and water volume is $200 \mathrm{~mL}$.

Undoubtedly, the source of $\mathrm{OH}$ radicals is water, and the formation of these radicals involves multiple pathways, which include an electron impact dissociation $\left(\mathrm{e}+\mathrm{H}_{2} \mathrm{O} \rightarrow \mathrm{OH}+\right.$ $\mathrm{H}+\mathrm{e})$, a dissociative electron attachment $\left(\mathrm{e}+\mathrm{H}_{2} \mathrm{O} \rightarrow \mathrm{OH}+\mathrm{H}^{-}\right)$, an electron-ion dissociative recombination ( $\mathrm{e}+\mathrm{H}_{2} \mathrm{O}^{+} \rightarrow \mathrm{OH}+\mathrm{H}$ and $\mathrm{e}+\mathrm{H}_{3} \mathrm{O}^{+} \rightarrow \mathrm{OH}+\mathrm{H}_{2}$ ), a positive-negative ion recombination $\left(\mathrm{H}^{-}+\mathrm{H}_{3} \mathrm{O}^{+} \rightarrow \mathrm{OH}+\mathrm{H}_{2}+\mathrm{H}\right)$, a dissociation with metastable atom $\left(\mathrm{Ar}^{*}+\mathrm{H}_{2} \mathrm{O}\right.$ $\rightarrow \mathrm{OH}+\mathrm{H}+\mathrm{Ar})$, and a charge exchange $\left(\mathrm{Ar}^{+}+\mathrm{H}_{2} \mathrm{O} \rightarrow \mathrm{OH}+\mathrm{ArH}^{+}\right)$. Meanwhile, the $\mathrm{NH}$ emission can be magnified with the addition of $\mathrm{N}_{2}$. The effects of the additive $\mathrm{N}_{2}$ on the $\mathrm{Ar}$ plasma kinetics in a gaseous system have been previously investigated, both theoretically [33, 34] and experimentally [30]. In an Ar- $\mathrm{N}_{2}$ gas mixture, a plasma generates nitrogen species, such as $\mathrm{N}, \mathrm{N}_{2}{ }^{*}$, and $\mathrm{N}_{2}{ }^{+}$, in various excited levels in addition to $\mathrm{Ar}^{*}$ and $\mathrm{Ar}^{+}$. Therefore, it is feasible that these chemically reactive species, together with electrons, effectively interact with the water vapor, which could then generate atomic and molecular species, such as $\mathrm{H}, \mathrm{O}$, and $\mathrm{OH}$. The production of $\mathrm{NH}$ in $\mathrm{N}_{2}-\mathrm{H}_{2}$ has been investigated by Van Helden et al. [35], and they suggested the following formation mechanisms: $\mathrm{N}+\mathrm{H}_{2} \rightarrow \mathrm{NH}+\mathrm{H}$ and/or $\mathrm{N}^{+}+\mathrm{H}_{2} \rightarrow \mathrm{NH}+$ $\mathrm{H}^{+}$. In fact, these reactions are proposed for $\mathrm{N}_{2}-\mathrm{H}_{2}$ plasma at conditions relatively far from those of our submerged MWPJ, where $\mathrm{O}$ and $\mathrm{OH}$ should be added to the proposed reactions. The 
formation of $\mathrm{NH}$ radicals in such conditions may indicate a complex chemistry in in-liquid plasma, but this needs to be further clarified by, for example, performing simulation studies.

\subsection{Application to methylene blue degradation}

To assess a potential applicability of the submerged MWPJ to wastewater treatment, we select $\mathrm{MB}$ as a simulated organic contaminant. $\mathrm{MB}$ has been widely investigated in a water treatment field, which makes it suitable to draw valid comparisons. In the present study, we maintain a MB concentration at $50 \mathrm{mg} / \mathrm{L}$. Figure 11 shows the normalized absorbance, which is obtained by the spectrophotometer, at $663 \mathrm{~nm}$ after 15 minutes of plasma processing for various gas mixtures (99\% of $\mathrm{Ar}$ and $1 \%$ of $\mathrm{O}_{2}$, air, or $\mathrm{N}_{2}$, respectively) with a fixed $\mu \mathrm{WP}=$ $200 \mathrm{~W}$. Based on the relative absorbance values shown in the figure, we find that treatment performances (i.e., degree of decolorization) with $\mathrm{Ar}-\mathrm{N}_{2}$ and $\mathrm{Ar}$-air mixtures are higher than those with other mixtures ( $\mathrm{Ar}-\mathrm{O}_{2}$ and pure Ar). Since the decolorization with added oxygen is the least efficient, it can be concluded that nitrogen is a key factor in obtaining a greater performance with the Ar-air mixture. Thus, we further investigate the effect of the addition of $\mathrm{N}_{2}$ on the decolorization process.

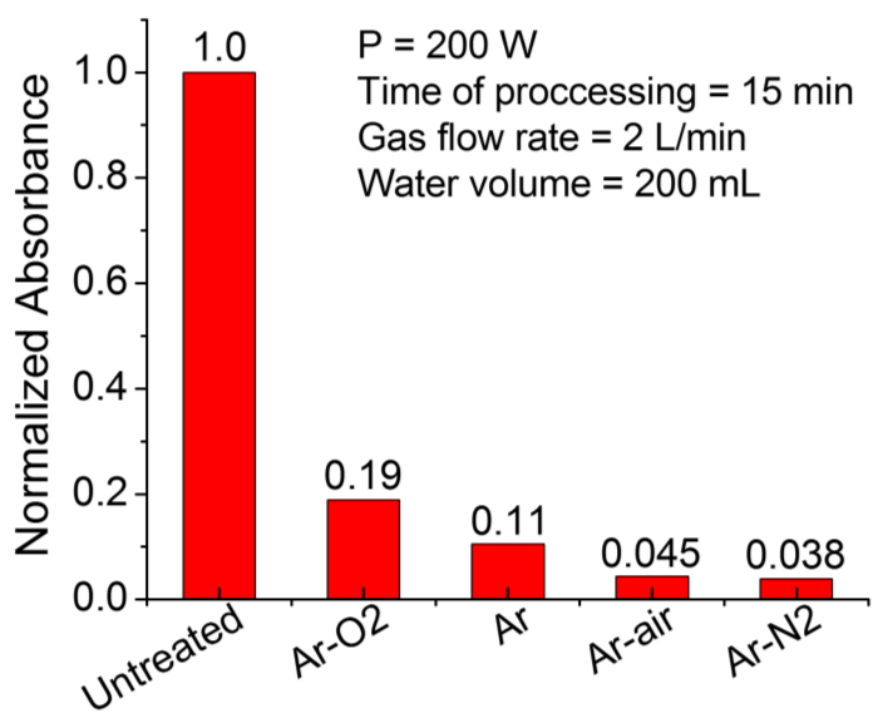

Fig. 11 Normalized absorbance variation for $M B$ in terms of gas mixture (99\% of Ar and $1 \%$ of $\mathrm{O}_{2}$, air, or $\mathrm{N}_{2}$ ) after $15 \mathrm{~min}$ plasma processing; $\mu W P$ is $200 \mathrm{~W}$, total gas flow rate is $2 \mathrm{~L} / \mathrm{min}$, and water volume is $200 \mathrm{~mL}$. The absorbance is measured by the spectrophotometer.

Figure 12 represents the variation of the absorbance at $663 \mathrm{~nm}$ (normalized to the case with pure Ar, i.e. $0 \% \mathrm{~N}_{2}$ ) as a function of the percentage of $\mathrm{N}_{2}$ in the gas mixture. In this figure, we clearly find that an optimum efficiency of the decolorization process is obtained for a nitrogen percentage of $2.5 \%$. Based on the results obtained with emission intensities at various 
$\mathrm{N}_{2}$ percentages in the pure water (figure 10), we postulate that an increase in NH radicals (for small additions of $\mathrm{N}_{2}$ ) could play an important role in the decolorization process. In addition to the emitted energetic photons (wavelength $330-340 \mathrm{~nm}$ ), $\mathrm{NH}$ radicals have a relatively high redox potential $(\sim 1 \mathrm{~V})[36]$, therefore these may significantly contribute to the decomposition of MB.

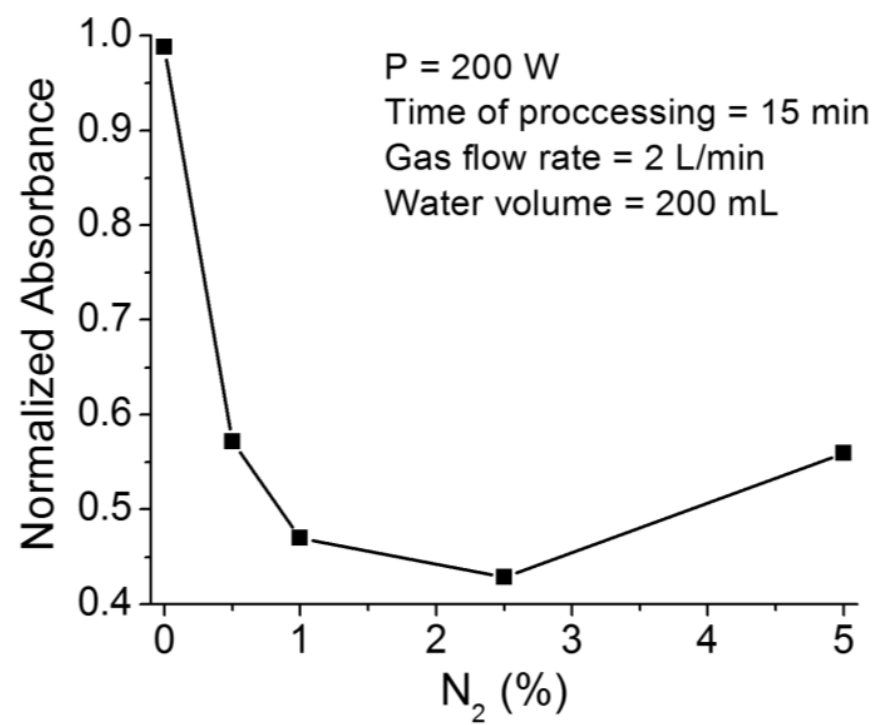

Fig. 12 Normalized absorbance for $M B$ with respect to the pure Ar case $\left(0 \% \mathrm{~N}_{2}\right)$ as a function of $\mathrm{N}_{2}$ percentage in a Ar- $N_{2}$ gas mixture. The plasma processing time is 15 minutes, $\mu \mathrm{WP}$ is $200 \mathrm{~W}$, total gas flow rate is $2 \mathrm{~L} / \mathrm{min}$, and water volume is $200 \mathrm{~mL}$. The absorbance is measured by the spectrophotometer.

We should note that, with no addition of $\mathrm{N}_{2}$, the $\mathrm{OH}$ radicals produced in the plasma are easily converted to $\mathrm{H}_{2} \mathrm{O}_{2}[1,12]$, resulting in the deterioration of the oxidation potential of $\mathrm{OH}$ radicals. However, adding $\mathrm{N}_{2}$ leads to the formation of $\mathrm{NO}$ and $\mathrm{NO}_{2}$, which can significantly inhibit the consumption of $\mathrm{OH}$ radicals via the following backward reactions $[12,38]: \mathrm{H}_{2} \mathrm{O}_{2}+$ $\mathrm{NO} \rightarrow \mathrm{HNO}_{2}+\mathrm{OH}$ and $\mathrm{H}_{2} \mathrm{O}_{2}+\mathrm{NO}_{2} \rightarrow \mathrm{HNO}_{3}+\mathrm{OH}$. This secondary effect of $\mathrm{N}_{2}$ addition may also create a favorable environment for the decomposition of MB. In fact, the induced chemistry in such a medium is very wide, and many other species that can contribute to MB degradation can be produced. For instance, water temperature increases significantly (to $\sim 70{ }^{\circ} \mathrm{C}$ ), and it has been observed, by Benetoli et al. [37], that dye decolorization increased with an increase in solution temperature. Also, other oxidizing species, such as peroxonitrous acid (ONOOH), can be produced in our conditions $\left(\right.$ e.g., $\left.\mathrm{H}^{+}+\mathrm{NO}_{2}{ }^{-}+\mathrm{H}_{2} \mathrm{O}_{2} \rightarrow \mathrm{ONOOH}+\mathrm{H}_{2} \mathrm{O}\right)$ and can contribute to $\mathrm{MB}$ degradation [38].

We also investigate the normalized absorbance as a function of plasma processing time (figure 13a), at $\mu \mathrm{WP}=200 \mathrm{~W}$ with $1 \% \mathrm{~N}_{2}$. The trend of the change in the absorbance can be 
separated into two phases; the first phase, from 0 to 12 minutes, during which the absorbance exhibits a rapid drop resulting in a $95 \%$ reduction, and the second phase, from 12 to 45 minutes, during which the absorbance shows a slow decay. The time evolution of the absorbance is proportional to the concentration of $\mathrm{MB}$ in water. The evolution shows various slopes indicating therefore that there are different phases of the reaction that can be zero-, first-, and secondorder.
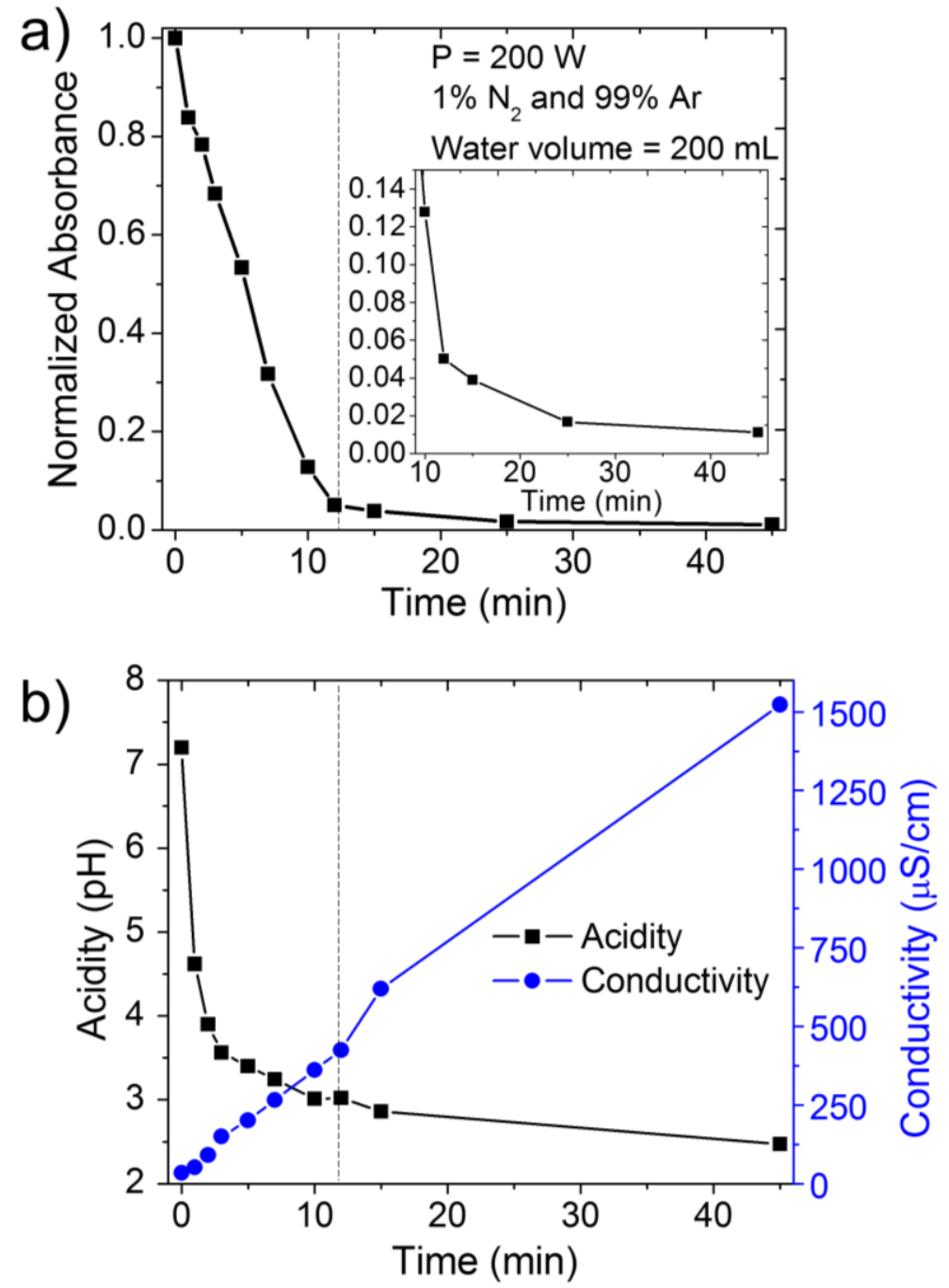

Fig. 13 Time evolution of a) the absorption for MB and of $b$ ) acidity and water conductivity; $\mu W P$ is 200 $W$, total gas flow rate is $2 \mathrm{~L} / \mathrm{min}$, and water volume is $200 \mathrm{~mL}$.

We also study the time evolution of acidity and electrical conductivity of the plasma treated MB-contained water along the plasma processing time (figure 13b). During the first phase, from 0 to 12 minutes, we observe a fast decrease in the acidity, from $\sim 7.2$ to $\sim 3 \mathrm{pH}$. During the second phase, from 12 to 45 minutes, the acidity slowly decreases from $\sim 3$ to $\sim 2.5$ $\mathrm{pH}$. The time trend of the conductivity shows a linear increase from 10 to $\sim 1500 \mu \mathrm{S} / \mathrm{cm}$. In fact, the acidity of the plasma treated MB-contained water is related to the concentration of $\mathrm{H}_{3} \mathrm{O}^{+}$in 
the solution, and the conductivity is related to the concentration of anions and cations in the solution. These ions can be created either by the by-products of the MB decomposition or by $\mathrm{NO}_{2}{ }^{-}$and $\mathrm{NO}_{3}{ }^{-}$produced in the plasma containing $\mathrm{N}_{2}$.

We conduct additional experiments using pure distilled water (initial condition: conductivity $=10 \mu \mathrm{S} / \mathrm{cm}$, acidity $=7.2 \mathrm{pH}$ ) and compare the results of the acidity and the conductivity with those of MB-contained water (initial condition: conductivity $=34 \mu \mathrm{S} / \mathrm{cm}$, acidity $=7.2 \mathrm{pH}$ ). In this way, we are able to roughly distinguish the origins of ions dissolved in the water, which affect the decreased solution acidity and increased conductivity. Comparing the case $\mathrm{A}$ (pure distilled water) and the case $\mathrm{C}$ (distilled water treated by Ar plasma) in figure 14, the significant decrease in the acidity and increase in the conductivity can be attributed mainly to the production of $\mathrm{H}_{3} \mathrm{O}^{+}$via the following reactions: $\mathrm{e}+\mathrm{H}_{2} \mathrm{O} \rightarrow \mathrm{H}_{2} \mathrm{O}^{+}+2 \mathrm{e}$ then $\mathrm{H}_{2} \mathrm{O}^{+}$ $+\mathrm{H}_{2} \mathrm{O} \rightarrow \mathrm{H}_{3} \mathrm{O}^{+}+\mathrm{OH}$ ). For the case $\mathrm{D}$ (MB-contained water treated by Ar plasma) as compared to the case $\mathrm{C}$, further increased conductivity and decreased acidity can be considered as a result of by-products from MB decomposition due to the plasma induced chemical reactions. To investigate the various reactions that can take place, a quantitative study should be conducted to identify and quantify the by-products in gas-phase as well as in liquid-phase. For the case E (distilled water treated by Ar- $(1 \%) \mathrm{N}_{2}$ plasma), the increased conductivity and decreased acidity relative to the case $\mathrm{C}$ should be caused by ions originated by nitrogen, such as $\mathrm{NO}_{2}^{-}, \mathrm{NO}_{3}{ }^{-}$, $\mathrm{HNO}_{2}$, and $\mathrm{HNO}_{3}$. Thus, the results with the case $\mathrm{F}\left(\mathrm{MB}\right.$-contained water treated by $\operatorname{Ar}-(1 \%) \mathrm{N}_{2}$ plasma) should be attributed to the combined effects of $\mathrm{H}_{3} \mathrm{O}^{+}, \mathrm{NO}_{2}{ }^{-}, \mathrm{NO}_{3}{ }^{-}$, and the by-product from MB decomposition.

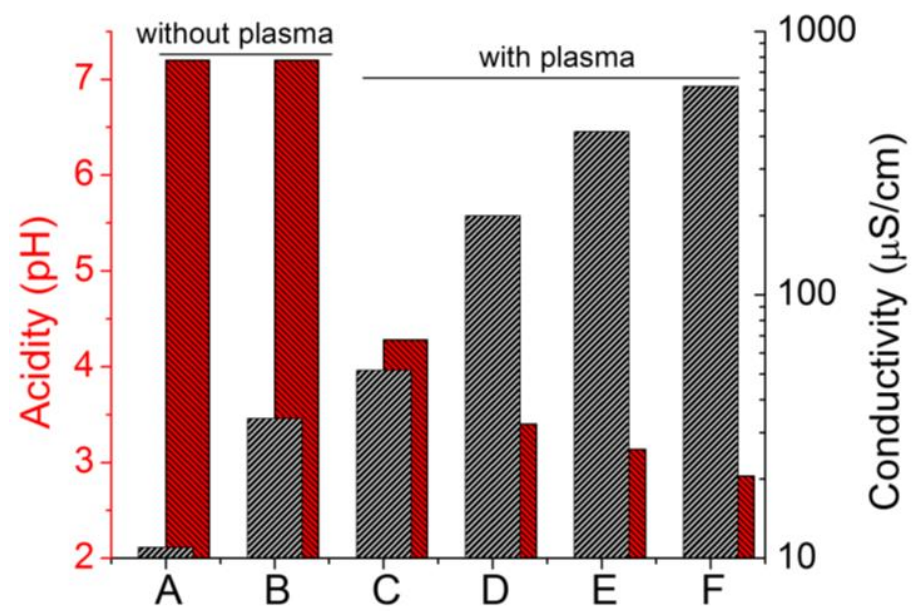

Fig. 14 Acidity and electrical conductivity of water before and after 15 minutes of plasma processing under various conditions of water and gas compositions; $A$ (pure distilled water), $B$ (MB contained distilled water), $C$ (distilled water treated by Ar plasma), D (MB-contained distilled water treated by Ar plasma), E (distilled water treated by Ar- $(1 \%) N_{2}$ plasma), and $F(M B$ contained distilled water treated by Ar-(1\%)N $N_{2}$ plasma). $\mu W P$ is $200 \mathrm{~W}$, total gas flow rate is 2 $\mathrm{L} / \mathrm{min}$, and water volume is $200 \mathrm{~mL}$. 
Finally, we calculate the energy yield $Y$ for MB decolorization using the following expression [28]:

$$
Y(g / k W h)=\frac{V(L) C_{0}(g / L) \frac{C_{0}-C}{C_{0}}}{P(k W) \times t(h)}
$$

where $V$ is the water volume, $C_{0}$ is the initial MB concentration, and $C$ is the concentration of MB in the solution after treatment during a time $t$ at power $P$. The yield to remove $50 \%$ of $\mathrm{MB}$, $Y_{50 \%}$, is thus estimated as $0.3 \mathrm{~g} / \mathrm{kWh}$. Table 1 provides a list of various plasma reactors used for MB removal as well as the $Y_{50 \%}$. Compared to MWPJ in contact with water, the yield of the submerged one is 10 times higher $\left(0.3 v s\right.$. 0.03). Pulsed corona discharges in-water with $\mathrm{O}_{2}$ gas or in-contact with water with $\mathrm{O}_{2}$ bubbles have the highest yield, i.e., 0.341 and 1.5, respectively.

Table 1 Energy yields to remove $50 \%$ of $M B, Y_{50 \%}$, reported in various plasma reactors.

\begin{tabular}{|c|c|c|c|}
\hline $\begin{array}{l}\text { MB concentration } \\
(\mathrm{mg} / \mathrm{L})\end{array}$ & Type of plasma reactor & $\begin{array}{c}\mathrm{Y}_{50 \%} \\
(\mathrm{~g} / \mathrm{kWh})\end{array}$ & Ref. \\
\hline 50 & Submerged MWPJ & 0.3 & This work \\
\hline 50 & MWPJ in contact with water & 0.033 & [28] \\
\hline 12 & Diaphragm discharges & 0.042 & [39] \\
\hline 5 & Radio-frequency discharges & 0.037 & [40] \\
\hline 10 & $\begin{array}{l}\text { Microwave discharges in water } \\
\text { with air bubbling }\end{array}$ & 0.155 & [41] \\
\hline 13.25 & $\begin{array}{l}\text { Pulsed corona discharges in water } \\
\text { with } \mathrm{O}_{2} \text { bubbling }\end{array}$ & 0.341 & [42] \\
\hline 13 & Pulsed corona discharges in water & 0.064 & [42] \\
\hline 15 & $\begin{array}{c}\mathrm{O}_{2} \text { pulsed corona discharges in } \\
\text { contact with water }\end{array}$ & 1.5 & [43] \\
\hline
\end{tabular}

\section{CONCLUSION}

We develop a submerged microwave plasma jet (MWPJ) system in water to enhance an applicability of plasmas in-liquid. It should have few advantages; i) somewhat independent plasma generation of physical properties of liquid, ii) facilitated chemical process due to both electron- and thermally induced chemistry, iii) increased volume of plasma-liquid interaction, and iv) turbulent mixing. Particularly, this proposed method has no influence of electrode erosion on treated liquids.

We investigate the physical characteristics of the submerged MWPJ in water. The plasma dynamics as well as the bubble dynamics are investigated using high-speed imaging, highlighting the effects of Ar flow rate and microwave power on them. We find that the plasma 
length increases with either increased gas flow rate or increased microwave power. Due to the anisotropic expansion of a gas bubble caused by horizontally injected MWPJ, a significant interaction between a plasma channel and the lower part of bubble-water interface can cause a retreating plasma channel resulting in its total extinction even before a bubble detachment from the inlet of MWPJ. We also show that the addition of $\mathrm{N}_{2}$ to Ar highly affects the plasma dynamics exhibiting an extinction of plasma for the $\mathrm{N}_{2}$ portion is higher than $5 \%$ while, at the percentage $<5 \%$, an oscillatory behavior of the discharge channel is found. A characterization by an optical emission spectroscopy shows that, in the case of Ar plasma, the spectrum is dominated by $\mathrm{OH}(\mathrm{A}-\mathrm{X})$ band and by $\mathrm{Ar} \mathrm{I}$ lines, including discernable $\mathrm{H}(\alpha, \beta$, and $\gamma), \mathrm{O}$, and the $\mathrm{NH}(\mathrm{A}-\mathrm{X})$ band, indicating effective dissociation of water via plasma chemistry. As a result of $\mathrm{N}_{2}$ addition, an intense emission of $\mathrm{NH}$ is observed with additional excited $\mathrm{N}_{2}$ and $\mathrm{N}_{2}{ }^{+}$ emissions.

In order to assess the feasibility of the submerged MWPJ to in-liquid chemical processes, we perform a wastewater treatment experiment by selecting methylene blue as a model organic contaminant. We compare the decolorization performance by changing additive gas $\left(\mathrm{N}_{2}, \mathrm{O}_{2}\right.$, and air) to Ar. As a result, we find that $\mathrm{N}_{2}$ is the most effective additive among tested, due to the backward reactions of $\mathrm{H}_{2} \mathrm{O}_{2}$ to produce $\mathrm{OH}$ radicals caused by $\mathrm{NO}$ and $\mathrm{NO}_{2}$ as well as a potential redox capability of NH radicals. Particularly, we show that the addition of 1 to $3 \%$ of $\mathrm{N}_{2}$ increases the decolorization efficiency exhibiting more than $90 \%$ of $\mathrm{MB}$ is decomposed during the first 10 minutes of processing for the initial MB concentration of 50 $\mathrm{mg} / \mathrm{L}$. This result shows that the submerged MWPJ can be used for efficient in-liquid chemical processes, avoiding an issue with electrode erosion encountered in other plasma devices.

\section{Acknowledgement}

The research reported in this publication was supported by funding from King Abdullah University of Science and Technology (KAUST), under award number BAS/1/1384-01-01. 


\section{REFERENCES}

[1] Locke B R and Shih K Y (2011) Review of the methods to form hydrogen peroxide in electrical discharge plasma with liquid water. Plasma Sources Science and Technology, 20(3), p. 034006.

[2] Lebedev Y A (2017) Microwave discharges in liquid dielectrics. Plasma Physics Reports, 43(6), p. 685.

[3] Foster JE (2017) Plasma-based water purification: Challenges and prospects for the future. Physics of Plasmas, 24(5), p.055501.

[4] Ceccato P H, Guaitella O, Le Gloahec M R and Rousseau A (2010) Time-resolved nanosecond imaging of the propagation of a corona-like plasma discharge in water at positive applied voltage polarity. Journal of Physics D: Applied Physics, 43(17), p. 175202.

[5] Hamdan A and Cha M S (2016) Low-dielectric layer increases nanosecond electric discharges in distilled water. AIP Advances, 6(10), p. 105112.

[6] Marinov I, Starikovskaia S and Rousseau A (2014) Dynamics of plasma evolution in a nanosecond underwater discharge. Journal of Physics D: Applied Physics, 47(22), p. 224017.

[7] Laurita R, Barbieri D, Gherardi M, Colombo V and Lukes P (2015) Chemical analysis of reactive species and antimicrobial activity of water treated by nanosecond pulsed DBD air plasma. Clinical Plasma Medicine, 3(2), p. 53-61.

[8] Tian W and Kushner M J (2014) Atmospheric pressure dielectric barrier discharges interacting with liquid covered tissue. Journal of Physics D: Applied Physics, 47(16), p. 165201.

[9] Robert E, Darny T, Dozias S, Iseni S and Pouvesle J M (2015) New insights on the propagation of pulsed atmospheric plasma streams: From single jet to multi jet arrays. Physics of Plasmas, 22(12), p. 122007.

[10] Surov A V, Popov S D, Popov V E, Subbotin D I, Serba E O, Spodobin V A, Nakonechny G V and Pavlov A V (2017) Multi-gas AC plasma torches for gasification of organic substances. Fuel, 203, p. 1007-1014.

[11] Chang J S (2001) Recent development of plasma pollution control technology: a critical review. Science and Technology of Advanced Materials, 2(3-4), p. 571-576.

[12] Liu J L, Park H W, Hamdan A, Cha M S (2018) In-liquid arc plasma jet and its application to phenol degradation. Journal of Physics D: Applied Physics, 51, p. 114005.

[13] Liedtke K R, Bekeschus S, Kaeding A, Hackbarth C, Kuehn J P, Heidecke C D, Bernstorff W, Woedtke T and Partecke L I (2017) Non-thermal plasma-treated solution demonstrates antitumor activity against pancreatic cancer cells in vitro and in vivo. Scientific reports, 7(1), p. 8319.

[14] Tanaka H, Ishikawa K, Mizuno M, Toyokuni S, Kajiyama H, Kikkawa F, Metelmann H R and Hori M (2017) State of the art in medical applications using non-thermal atmospheric pressure plasma. Reviews of Modern Plasma Physics, 1(1), p. 3.

[15] Magureanu M, Mandache N B and Parvulescu V I (2015) Degradation of pharmaceutical compounds in water by non-thermal plasma treatment. Water research, 81, p.124-136.

[16] Hamdan A, Marinov I, Rousseau A and Belmonte T (2013) Time-resolved imaging of nanosecond-pulsed micro-discharges in heptane. Journal of Physics D: Applied Physics, 47(5), p. 055203.

[17] Hamdan A and Cha M S (2015) Ignition modes of nanosecond discharge with bubbles in distilled water. Journal of Physics D: Applied Physics, 48(40), p. 405206.

[18] Hamdan A and Cha M S (2016) The effects of gaseous bubble composition and gap distance on the characteristics of nanosecond discharges in distilled water. Journal of Physics D: Applied Physics, 49(24), p. 245203. 
[19] Hamdan A, Noel C, Kosior F, Henrion G and Belmonte T (2013) Impacts created on various materials by micro-discharges in heptane: Influence of the dissipated charge. Journal of Applied Physics, 113(4), p. 043301.

[20] Hamdan A, Kabbara H, Noël C, Ghanbaja J, Redjaimia A and Belmonte T (2018) Synthesis of two-dimensional lead sheets by spark discharge in liquid nitrogen. Particuology, https://doi.org/10.1016/j.partic.2017.10.012.

[21] Belmonte T, Hamdan A, Kosior F, Noël C and Henrion G (2014) Interaction of discharges with electrode surfaces in dielectric liquids: application to nanoparticle synthesis. Journal of Physics D: Applied Physics, 47(22), p. 224016.

[22] Tu Y, Xian Y, Yang Y, Lu X and Pan Y (2017) Time-resolved imaging of electrical discharge development in multiple bubbles immersed in water. Plasma Processes and Polymers, 14(10).

[23] Hamdan A and Cha M S (2016) Nanosecond Discharge in Bubbled Liquid n-Heptane: Effects of Gas Composition and Water Addition. IEEE Transactions on Plasma Science, 44(12), p. 2988-2994.

[24] Zhang $X$ and Cha M S (2015) The reformation of liquid hydrocarbons in an aqueous discharge reactor. Journal of Physics D: Applied Physics, 48(21), p. 215201.

[25] Dai X J, Corr C S, Ponraj S B, Maniruzzaman M, Ambujakshan A T, Chen Z, Kviz L, Lovett R, Rajmohan G D, de Celis D R and Wright M L (2016) Efficient and selectable production of reactive species using a nanosecond pulsed discharge in gas bubbles in liquid. Plasma Processes and Polymers, 13(3), p. 306-310.

[26] Tian W, Tachibana K and Kushner M J (2013) Plasmas sustained in bubbles in water: optical emission and excitation mechanisms. Journal of Physics D: Applied Physics, 47(5), p. 055202.

[27] Barkhudarov E M, Kossyi I A, Misakyan M A, Taktakishvili I M (2012) Microwave Discharges: Fundamentals and Applications, Ed. by Yu. A. Lebedev (Yanus-K, Moscow, 2012), p. 159.

[28] García M C, Mora M, Esquivel D, Foster J E, Rodero A, Jiménez-Sanchidrián C and Romero-Salguero F J (2017) Microwave atmospheric pressure plasma jets for wastewater treatment: degradation of methylene blue as a model dye. Chemosphere, 180, p 239-246.

[29] Cardoso R P, Belmonte T, Keravec P, Kosior F and Henrion G (2007) Influence of impurities on the temperature of an atmospheric helium plasma in microwave resonant cavity. Journal of Physics D: Applied Physics, 40(5), p. 1394.

[30] Bravo J A, Rincón R, Muñoz J, Sánchez A and Calzada M D (2015) Spectroscopic Characterization of Argon-Nitrogen Surface-Wave Discharges in Dielectric Tubes at Atmospheric Pressure. Plasma Chemistry and Plasma Processing, 35(6), p. 993-1014.

[31] Chen C J, Li S Z, Zhang J and Liu D (2017) Temporally resolved diagnosis of an atmospheric-pressure pulse-modulated argon surface wave plasma by optical emission spectroscopy. Journal of Physics D: Applied Physics, 51(2), p. 025201.

[32] Itikawa Y (2006) Cross sections for electron collisions with nitrogen molecules. Journal of physical and chemical reference data, 35(1), p. 31-53.

[33] Bogaerts A (2009) Hybrid Monte Carlo-Fluid model for studying the effects of nitrogen addition to argon glow discharges. Spectrochimica Acta Part B: Atomic Spectroscopy, 64(2), p. 126-140.

[34] Henriques J, Tatarova E, Guerra V and Ferreira C M (2002) Wave driven $\mathrm{N}_{2}$-Ar discharge. I. Self-consistent theoretical model. Journal of applied physics, 91(9), p. 5622-5631

[35] Van Helden J H, Van den Oever P J, Kessels W M M, Van de Sanden M C M, Schram D $\mathrm{C}$ and Engeln R (2007) Production Mechanisms of NH and NH2 Radicals in N2- H2 Plasmas. The Journal of Physical Chemistry A, 111(45), p.11460-11472. 
[36] Jonsson M, Lind J, Merényi G and Eriksen T E (1995) N-H bond dissociation energies, reduction potentials and $\mathrm{p} \mathrm{K}$ as of multisubstituted anilines and aniline radical cations. Journal of the Chemical Society, Perkin Transactions 2, (1), p. 61-65

[37] Benetoli L O D B, Cadorin B M, Postiglione C D S, Souza I G D and Debacher N A (2011) Effect of temperature on methylene blue decolorization in aqueous medium in electrical discharge plasma reactor. Journal of the Brazilian Chemical Society, 22(9), p.1669-1678.

[38] Moussa D, Doubla A, Kamgang-Youbi G and Brisset J L (2007) Postdischarge long life reactive intermediates involved in the plasma chemical degradation of an azoic dye. IEEE Transactions on plasma science, 35(2), p.444-453.

[39] Stará Z, Krčma F, Nejezchleb M and Skalný J D (2009) Organic dye decomposition by DC diaphragm discharge in water: Effect of solution properties on dye removal. Desalination, 239(1-3), p.283-294.

[40] Maehara T, Miyamoto I, Kurokawa K, Hashimoto Y, Iwamae A, Kuramoto M, Yamashita $\mathrm{H}$, Mukasa S, Toyota H, Nomura S and Kawashima A (2008) Degradation of methylene blue by RF plasma in water. Plasma Chemistry and Plasma Processing, 28(4), p.467-482.

[41] Ishijima T, Hotta H, Sugai H and Sato M (2007) Multibubble plasma production and solvent decomposition in water by slot-excited microwave discharge. Applied Physics Letters, 91(12), p.121501.

[42] Malik M A, Ghaffar A and Ahmed K (2002) Synergistic effect of pulsed corona discharges and ozonation on decolourization of methylene blue in water. Plasma Sources Science and Technology, 11(3), p.236.

[43] Ikoma S, Satoh K and Itoh H (2009) Decomposition of methylene blue in an aqueous solution using a pulsed-discharge plasma at atmospheric pressure. IEEJ Transactions on Fundamentals and Materials, 129, p.237-244. 


\section{CAPTIONS}

Table 1 Energy yields to remove $50 \%$ of $\mathrm{MB}, \mathrm{Y}_{50 \%}$, reported in various plasma reactors.

Fig 1 Schematic of the experimental setup used to create submerged MWPJ: a) 3D view and b) 2D view.

Fig. 2 Plasma-bubble dynamics for various Ar flow rates at $\mu \mathrm{WP}=200 \mathrm{~W}$ and water volume $=200 \mathrm{~mL}$ : a) the argon flow rate of 1, b) 2 , c) 4 , and d) $5 \mathrm{~L} / \mathrm{min}$; e) is with the same condition as d) but retaken with a higher spatial resolution. The red arrow indicates the plasma inlet and flow direction.

Fig. 3 Time evolution of the plasma length and bubble length for various Ar flow rates at $\mu \mathrm{WP}=200$ $\mathrm{W}$ and water volume $=200 \mathrm{~mL}$ : a) with the argon flow rate of 1 , b) 2, c) 4 , and d) $5 \mathrm{~L} / \mathrm{min}$. These results are obtained from processing the high-speed images. The inset of a) shows the definition of the lengths; the plasma exit (left reference line) is determined based on the plane symmetry due to the reflection from the left side wall.

Fig. 4 Time evolution of the plasma length and bubble length for various $\mu$ WPs at the Ar flow rate is 2 $\mathrm{L} / \mathrm{min}$ and water volume is $200 \mathrm{~mL}:$ a) $\mu \mathrm{WP}=150 \mathrm{~W}$, b) $75 \mathrm{~W}$, c) $50 \mathrm{~W}$, and d) $25 \mathrm{~W}$.

Fig. 5 Optical emission spectra acquired at the inlet of the MWPJ to the liquid cell for four $\mu$ WPs (25, 50, 100, and $200 \mathrm{~W}$ ). Exposure time is $1 \mathrm{~ms}$, each spectrum is averaged 50 measurements, Ar flow rate is $2 \mathrm{~L} / \mathrm{min}$, and the water volume is $200 \mathrm{~mL}$.

Fig. 6 Experimental and synthetic spectra of $\mathrm{OH}(\mathrm{A}-\mathrm{X})$ at a) 25 and b) $200 \mathrm{~W}$, respectively. c) Rotational temperature variation as a function of $\mu \mathrm{WP}$; total Ar flow rate is $2 \mathrm{~L} / \mathrm{min}$ and water volume is 200 $\mathrm{mL}$.

Fig. 7 Temporal dynamics of $\mathrm{OH}(309 \pm 5 \mathrm{~nm})$ emission for various Ar flow rates; a) the argon flow rate of 1, b) 2 , and c) $5 \mathrm{~L} / \mathrm{min}$. $\mu \mathrm{WP}$ is $200 \mathrm{~W}$ and water volume is $200 \mathrm{~mL}$. The red arrow indicates the plasma inlet and flow direction.

Fig. 8 Plasma-bubble dynamics for two $\mathrm{N}_{2}$ percentages in Ar: a) 0.5 and b) $2 \%$. $\mu \mathrm{WP}$ is $200 \mathrm{~W}$, total gas flow rate is $2 \mathrm{~L} / \mathrm{min}$, and water volume is $200 \mathrm{~mL}$. The red arrow indicates the plasma inlet and flow direction.

Fig. 9 Time evolution of the plasma and bubble lengths for various $\mathrm{N}_{2}$ percentages in Ar flow: a) 0.5, b) 1, c) 1.5, d) 2 , and e) $3 \%$. The plasma lengths at $0 \% \mathrm{~N}_{2}$ (pure Ar) is superimposed each graph for comparison. Total gas flow rate is $2 \mathrm{~L} / \mathrm{min}, \mu \mathrm{WP}$ is $200 \mathrm{~W}$, and water volume is $200 \mathrm{~mL}$.

Fig. 10 Plasma optical emission spectra, in a range of 300-400 $\mathrm{nm}$ acquired at the inlet of the MWPJ into the liquid container for various $\mathrm{N}_{2}$ percentages. The integration time is $1 \mathrm{~ms}$, and spectra are averaged over 50 measurements; $\mu \mathrm{WP}$ is $200 \mathrm{~W}$, total gas flow rate is $2 \mathrm{~L} / \mathrm{min}$, and water volume is $200 \mathrm{~mL}$. 
Fig. 11 Normalized absorbance variation for $\mathrm{MB}$ in terms of gas mixture (99\% of $\mathrm{Ar}$ and $1 \%$ of $\mathrm{O}_{2}$, air, or $\mathrm{N}_{2}$ ) after 15 min plasma processing; $\mu \mathrm{WP}$ is $200 \mathrm{~W}$, total gas flow rate is $2 \mathrm{~L} / \mathrm{min}$, and water volume is $200 \mathrm{~mL}$. The absorbance is measured by the spectrophotometer.

Fig. 12 Normalized absorbance for $\mathrm{MB}$ with respect to the pure $\mathrm{Ar}$ case $\left(0 \% \mathrm{~N}_{2}\right)$ as a function of $\mathrm{N}_{2}$ percentage in a Ar- $\mathrm{N}_{2}$ gas mixture. The plasma processing time is 15 minutes, $\mu \mathrm{WP}$ is $200 \mathrm{~W}$, total gas flow rate is $2 \mathrm{~L} / \mathrm{min}$, and water volume is $200 \mathrm{~mL}$. The absorbance is measured by the spectrophotometer.

Fig. 13 Time evolution of a) the absorption for MB and of b) acidity and water conductivity; $\mu$ WP is $200 \mathrm{~W}$, total gas flow rate is $2 \mathrm{~L} / \mathrm{min}$, and water volume is $200 \mathrm{~mL}$.

Fig. 14 Acidity and electrical conductivity of water before and after 15 minutes of plasma processing under various conditions of water and gas compositions; A (pure distilled water), B (MB contained distilled water), C (distilled water treated by Ar plasma), D (MB-contained distilled water treated by Ar plasma), E (distilled water treated by $\operatorname{Ar}-(1 \%) \mathrm{N}_{2}$ plasma), and F (MB contained distilled water treated by $\operatorname{Ar}-(1 \%) \mathrm{N}_{2}$ plasma). $\mu \mathrm{WP}$ is $200 \mathrm{~W}$, total gas flow rate is 2 $\mathrm{L} / \mathrm{min}$, and water volume is $200 \mathrm{~mL}$. 